\title{
Abiotic stress responses in plants: roles of calmodulin-regulated proteins
}

\author{
Amardeep S. Virdi ${ }^{1}$, Supreet Singh ${ }^{2}$ and Prabhjeet Singh ${ }^{2 *}$ \\ ${ }^{1}$ Texture Analysis Laboratory, Department of Food Science \& Technology, Guru Nanak Dev University, Amritsar, India, ${ }^{2}$ Plant \\ Molecular Biology Laboratory, Department of Biotechnology, Guru Nanak Dev University, Amritsar, India
}

Intracellular changes in calcium ions $\left(\mathrm{Ca}^{2+}\right)$ in response to different biotic and abiotic stimuli are detected by various sensor proteins in the plant cell. Calmodulin (CaM) is one of the most extensively studied $\mathrm{Ca}^{2+}$-sensing proteins and has been shown to be involved in transduction of $\mathrm{Ca}^{2+}$ signals. After interacting with $\mathrm{Ca}^{2+}, \mathrm{CaM}$ undergoes conformational change and influences the activities of a diverse range of CaM-binding proteins. A number of CaM-binding proteins have also been implicated in stress responses in plants, highlighting the central role played by CaM in adaptation

OPEN ACCESS

Edited by:

Girdhar Kumar Pandey,

Delhi University, India

Reviewed by:

Ján A. Miernyk,

University of Missouri, USA

Lam-Son Tran,

RIKEN Center for Sustainable

Resource Science, Japan

*Correspondence:

Prabhjeet Singh,

Plant Molecular Biology Laboratory,

Department of Biotechnology, Guru

Nanak Dev University,

Amritsar 143005, Punjab, India

singhprabhjeet62@gmail.com

Specialty section: This article was submitted to Plant Physiology,

a section of the journal

Frontiers in Plant Science

Received: 01 June 2015

Accepted: 16 September 2015

Published: 14 October 2015

Citation:

Virdi AS, Singh S and Singh P (2015)

Abiotic stress responses in plants:

roles of calmodulin-regulated proteins.

Front. Plant Sci. 6:809.

doi: $10.3389 /$ fpls.2015.00809 to adverse environmental conditions. Stress adaptation in plants is a highly complex and multigenic response. Identification and characterization of CaM-modulated proteins in relation to different abiotic stresses could, therefore, prove to be essential for a deeper understanding of the molecular mechanisms involved in abiotic stress tolerance in plants. Various studies have revealed involvement of CaM in regulation of metal ions uptake, generation of reactive oxygen species and modulation of transcription factors such as CAMTA3, GTL1, and WRKY39. Activities of several kinases and phosphatases have also been shown to be modulated by CaM, thus providing further versatility to stress-associated signal transduction pathways. The results obtained from contemporary studies are consistent with the proposed role of CaM as an integrator of different stress signaling pathways, which allows plants to maintain homeostasis between different cellular processes. In this review, we have attempted to present the current state of understanding of the role of $\mathrm{CaM}$ in modulating different stress-regulated proteins and its implications in augmenting abiotic stress tolerance in plants.

Keywords: abiotic stress, $\mathrm{Ca}^{2+}$, calmodulin, calmodulin-binding proteins, plants

\section{Introduction}

Plants, being sessile, have evolved various biochemical and metabolic processes to sense developmental, hormonal, and environmental changes under normal and stress conditions. Of the various secondary messengers, such as hydrophobic- (diacylglycerol, phosphatidylinositol, etc.) and hydrophilic molecules ( $\mathrm{Ca}^{2+}$, cAMP, cGMP, IP3, etc.), and gases [nitric oxide (NO), carbon monoxide, etc.] in eukaryotes, the role of $\mathrm{Ca}^{2+}$ has been studied most extensively (Xiong et al., 2002). Different environmental, hormonal and developmental stimuli induce transient fluctuations in cytosolic $\mathrm{Ca}^{2+}\left(\left[\mathrm{Ca}^{2+}\right]_{\text {cyt }}\right)$ levels, the frequency and amplitude of which vary according to the strength of the signal (McCormack et al., 2005). These changes in $\mathrm{Ca}^{2+}$ signatures are decoded 
by an array of $\mathrm{Ca}^{2+}$-binding proteins such as (i) calcium modulating protein or calmodulin (CaM), (ii) CaM-like (CML) and other EF-hand containing $\mathrm{Ca}^{2+}$-binding proteins, (iii) $\mathrm{Ca}^{2+}$. dependent protein kinases (CDPKs), and (iv) calcineurin B-like proteins (Bouché et al., 2005 and references therein). Due to the differences in the number of EF-hand motifs, different $\mathrm{Ca}^{2+}$ relay sensors (CaM/CMLs) show variability in their affinity to $\mathrm{Ca}^{2+}$ since EF-hand motifs bind to $\mathrm{Ca}^{2+}$ cooperatively (Babu et al., 1988; McCormack et al., 2005).

CaM, the most well-characterized $\mathrm{Ca}^{2+}$ sensor, is an evolutionarily conserved, acidic, heat stable, and multifunctional protein consisting of two globular domains, each with two $\mathrm{Ca}^{2+}$-binding EF-hand motifs (Babu et al., 1988; Rhoads and Friedberg, 1997). Although CaM lacks its own catalytic activity, binding to or chelating of $\mathrm{Ca}^{2+}$ causes conformational changes in the globular domains leading to interaction with the target proteins (Snedden and Fromm, 2001; McCormack et al., 2005). Using CaM-binding transcription activators (CAMTA) for mathematical modeling, Liu et al. (2015) have recently demonstrated that interaction of $\mathrm{Ca}^{2+}{ }_{-} \mathrm{CaM}$ with the target proteins results in non-linear amplification of the $\mathrm{Ca}^{2+}$ signals, thereby allowing greater versatility to cells in deciphering different $\mathrm{Ca}^{2+}$ signatures for changes in gene expression. Contrary to humans, that contain only a single CaM protein (Fischer et al., 1988), multiple forms of this protein are reported in plants (McCormack et al., 2005; Al-Quraan et al., 2010). A total of seven genes encoding four different CaMs (CaM1/CaM4, CaM2/CaM3/CaM5, CaM6, and CaM7), that share a minimum 97\% identity at the primary sequence level, are observed in Arabidopsis thaliana (Bender and Snedden, 2013; Zhu et al., 2015 and references therein), whereas, 10 cDNAs encoding three CaM proteins have been predicted in wheat (Triticum aestivum; Yang et al., 1996). Similarly, rice (Oryza sativa) genome contains five true genes encoding two sets of CaM proteins (Boonburapong and Buaboocha, 2007). The OsCaM1 encoded by OsCaM1-1, OsCaM1-2, and OsCaM1-3 in rice differs by two amino acid residues from the CaM encoded by OsCaM2 and OsCaM3. Multiple genes for CaM i.e., four, six, and seven have been reported in potato (Solanum tuberosum), tomato (Lycopersicon esculentum) and tobacco (Nicotiana tabacum), respectively (Zhao et al., 2013). Molecular evolution of different CaMs and CMLs in plants has been reviewed extensively in a recent study (Zhu et al., 2015). Though primarily cytosolic, CaM is also localized in peroxisomes, plastids, mitochondria, the extracellular matrix, and nuclei (Jarrett et al., 1982; Roberts et al., 1983; Dauwalder et al., 1986; Ma et al., 1999; van Der Luit et al., 1999; Reddy et al., 2002; Yang and Poovaiah, 2002a), signifying versatility in its roles. Besides CaM, plants also contain CML proteins that show 16 to $75 \%$ amino acid identity with the former and are not reported in animals (McCormack et al., 2005). Arabidopsis genome is

\footnotetext{
Abbreviations: ABA, abscisic acid; $\mathrm{Ca}^{2+}$, calcium; CaM, calmodulin; CaM-KMT, CaM N-methyletransferase; cAMP, cyclic adenosine monophosphate; cGMP, cyclic guanosine monophosphate; HS, heat shock; IAA, indole-3-acetic acid; IP3: inositol 1,4,5-trisphosphate; IP6, myo-inositol hexaphosphate; NLSs, nuclear-localization signals; PA, phosphatidic acid; TFs, transcription factors; ROS, reactive oxygen species.
}

predicted to encode $50 \mathrm{CML}$ that show variable number of EF hands ranging from 1 (CML1) to 6 (CML12) (McCormack et al., 2005). Recent studies have demonstrated specific roles for some of the CMLs in developmental, hormonal and stress responses (Bender and Snedden, 2013). The proteins that bind to CaM do not show conservation in their primary amino acid sequence. However, the different CaM-binding proteins (CaMBPs) are characterized by the presence of amphiphilic $\alpha$-helical domains that interact with CaM through both hydrophobic and strong electrostatic interactions (O'Neil and DeGrado, 1990). Recent studies employing proteome microarray have revealed that of the 1133 Arabidopsis proteins tested, $\sim 25 \%$ showed interaction with one or the other isoform of CaM/CML (Popescu et al., 2007). However, interaction of most of these proteins with CaM/CML in vivo awaits validation by parallel strategies such as bimolecular fluorescence complementation (BiFC) or fluorescence resonance energy transfer (FRET) assays. The targets of CaM comprise a disparate group of proteins such as metabolic enzymes, kinases, transcription factors, etc., and have been reviewed extensively (Bouché et al., 2005; Reddy et al., 2011; Das et al., 2014). Since adverse environmental conditions pose major challenge to sustainable crop productivity, therefore, our discussion in this study will focus primarily on regulation by $\mathrm{CaM}$ of proteins that are implicated in abiotic stress response of plants.

\section{Expression of CaM and its Post-translational Modification}

The expression of genes encoding different CaM proteins in plants is affected differentially by phytohormones and environmental stresses, as was observed for MBCaM1 and MBCaM2 in Vigna radiate (Botella and Arteca, 1994). This study revealed that exogenous application of IAA and exposure to salt stress resulted in upregulation of $M B C a M 1$, whereas expression of MBCaM2 was not affected significantly. Though expression of both AtCaM3 and AtCaM7 was enhanced by heat shock in A. thaliana, the increase in transcript level of the former was observed earlier (Liu et al., 2005). Differential regulation of different $\mathrm{CaM}$ genes by diverse abiotic stress conditions can be attributed to differences in the upstream regulatory elements (Park et al., 2009; Jung et al., 2010; Chinpongpanich et al., 2012) that may enable the plants to respond in a stimulus-specific manner (Al-Quraan et al., 2010).

Post-translational methylation at Lysine-115 (L-115) is a prominent feature in most CaMs (Klee and Vanaman, 1982). L-115 methylation of CaM has been implicated in protection against adenosine triphosphate (ATP)-ubiquitindependent proteolysis that affects its intracellular levels (Gregori et al., 1985). Activity of target proteins can be affected differently by the CaM methylation status. This is also evident from earlier studies where activities of glutamate decarboxylase (GAD; Yun and Oh, 1998) and myosin light chain kinase in plants (Roberts et al., 1984) were shown to be independent of CaM methylation but activation of NAD kinase was adversely affected (Roberts et al., 1986; Harding et al., 1997). Role of methylation of $\mathrm{CaM}$ in regulating different cellular processes was further 
validated by overexpression of a synthetic gene encoding VU-3 CaM in transgenic tobacco plants. VU-3 CaM cannot undergo methylation due to substitution of L-115 with Arg. These transgenic plants showed impaired growth and development due to hyperactivation of a CaM-dependent NAD kinase, and consequent increase in NADPH and reactive oxygen species (ROS) levels (Harding et al., 1997). These studies provided evidence that CaM-methylation is critical for regulation of different developmental pathways in plants.

Methylation of CaM is catalyzed by CaM Nmethyletransferase (CaM-KMT), a highly conserved protein among eukaryotes (Magnani et al., 2010). Expression of CaMKMT gene is differentially modulated by phytohormones and abiotic stresses. Contrary to cytokinin (kinetin) that down-regulated CaM-KMT, the expression of this gene was shown to increase in response to auxin, salt-, and water stress (Banerjee et al., 2013), implying its role in hormone and stress signaling pathways. Overexpression of CaM-KMT and its suppression in Arabidopsis, resulting in hyper- and hypomethylation, respectively, were associated with attenuated and enhanced root length phenotype, respectively (Banerjee et al., 2013). Furthermore, the hypomethylated CaM lines also exhibited greater tolerance to abscisic acid (ABA), cold-, and salt stress, suggesting that methylated form of CaM might be interacting specifically with effector proteins of different stress signaling pathways. This conclusion was also supported by the observations that as compared to unmethylated $\mathrm{CaM}$, the methylated CaM showed specifically higher binding affinity with proteins such as germin-like proteins (GLP9 and GLP10), cytochrome P450 20A1 (CP20A), and N-xylose isomerase (Banerjee et al., 2013). CaM provides further versatility in fine tuning of cellular responses to different stimuli through alteration in its subcellular localization after post-translational modification, as observed for CaM53 in petunia (Petunia hybrida; Rodriguez-Concepcion et al., 1999). Plants contain several CMLs (Bender and Snedden, 2013) but studies on the regulation of these proteins by methylation have not been carried out yet. Methylation of CMLs, if demonstrated, may provide further flexibility in the regulation of different developmental and stress signaling pathways in plants.

\section{Role of CaM in Maintenance of $\mathrm{Ca}^{2+}$ Homeostasis}

In comparison to cell wall and organelles, where $\mathrm{Ca}^{2+}$ is in millimolar concentration, $\mathrm{Ca}^{2+}$ in the cytosol is maintained at relatively lower levels $(100-200 \mathrm{~nm})$ because higher concentration of this ion is toxic for phosphate-based energy systems (Bush, 1995; Reddy, 2001; Clapham, 2007). Intracellular levels of $\mathrm{Ca}^{2+}$ in cytoplasm and endomembrane system are regulated through control of influx and efflux mechanisms. Though, passive influx of $\mathrm{Ca}^{2+}$ into cytosol takes place through $\mathrm{Ca}^{2+}$-channels (Sanders et al., 1999), its efflux is an active process that is mediated by $\mathrm{Ca}^{2+} / \mathrm{H}^{+}$antiporters and $\mathrm{Ca}^{2+}$ pumps. Energy for this process is provided by ATP hydrolysis and proton motive force (Bush, 1995). Two types of $\mathrm{Ca}^{2+}$-ATPases, IIA and IIB, have been reported in plants and animals (Axelson and Palmgren, 1998). The endoplasmic reticulum (ER)-type $\mathrm{Ca}^{2+}$-ATPases are known as type IIA $\mathrm{Ca}^{2+}$ pumps and activity of these pumps is not regulated by CaM (Chung et al., 2000). On the contrary, the activity of type IIB $\mathrm{Ca}^{2+}$ pumps is stimulated by CaM (Malmström et al., 1997; Harper et al., 1998), and these proteins are localized to tonoplast (Malmström et al., 1997), plasma membrane (PM; Bonza et al., 2000), chloroplast inner membrane (Huang et al., 1993), and ER (Hong et al., 1999).

Expression of $\mathrm{Ca}^{2+}$-ATPase encoding genes is differentially modulated under different stress conditions. Exposure to high salt $(\mathrm{NaCl})$ concentrations and fungal elicitor was observed to enhance the expression of soybean $\mathrm{Ca}^{2+}$-ATPase encoding SCA1 gene, whereas, addition of mannitol and $\mathrm{KCl}$ had no apparent effect (Chung et al., 2000). The SCA1 protein consists of two CaM-binding domains (CaMBDs) at amino acid residues 1-40 and 52-71, respectively, in the $\mathrm{N}$-terminus region and binds to $\mathrm{CaM}$ in a $\mathrm{Ca}^{2+}$-dependent manner. The ATPase activity of SCA1 is stimulated following its interaction with $\mathrm{Ca}^{2+}{ }_{-} \mathrm{CaM}$. The Nterminus domain is autoinhibitory for ATPase activity of SCA1 since deletion of this region resulted in activity that was similar to native protein assayed in the presence of $\mathrm{Ca}^{2+}-\mathrm{CaM}$. Though Chung et al. (2000) did not study whether stress-induced increase in mRNA transcripts of SCA1 was accompanied by an increase in the corresponding protein, it is likely that enhanced levels of this enzyme may be contributing to lowering of $\mathrm{Ca}^{2+}$ to the basal levels so as to prevent $\mathrm{Ca}^{2+}$ toxicity (Clapham, 2007). It appears that regulation of $\mathrm{Ca}^{2+}$ levels through $\mathrm{Ca}^{2+}$-pumps, which are modulated by $\mathrm{CaM}$, appears to be a part of feedback mechanism that maintains $\mathrm{Ca}^{2+}$ homeostasis in the cell. Since canonical and divergent $\mathrm{CaM}$ isoforms are reported to bind differentially to one of the Arabidopsis $\mathrm{Ca}^{2+}$-ATPases (AtACA8; Luoni et al., 2006), systematic studies on the kinetics of stress-induced changes in $\left[\mathrm{Ca}^{2+}\right]_{\mathrm{cyt}}$, and expression of different $\mathrm{Ca}^{2+}$-ATPases and $\mathrm{CaM}$ isoforms are required to elucidate the mechanism of this feedback regulation.

\section{Regulation of Glutamate Decarboxylase by CaM}

$\gamma$-Amino butyric acid (GABA) is an ubiquitously found nonprotein amino acid. Characterized as a neurotransmission inhibitor of central nervous system in animals (Mody et al., 1994; Hampe et al., 2001), the role of this molecule is still a matter of speculation in plants. GABA is produced as a result of glutamate decarboxylation, catalyzed by GAD. The basic structure of animal and plant GADs is conserved (Ueno, 2000) and these proteins show $75-86 \%$ similarity at the protein sequence level (Gallego et al., 1995; Johanson et al., 1997; Turano and Fang, 1998; Yun and Oh, 1998; Akama et al., 2001; Bouché et al., 2004; Oh et al., 2005; Lee et al., 2010). The genes encoding GADs in plants are present in multiple copies, with five copies each predicted in the genomes of rice as well as Arabidopsis (Akama and Takaiwa, 2007). Expression of different GAD isoforms in plants is regulated in a tissue-dependent manner and is induced by different abiotic stresses such as heat-, osmotic-, 
and oxidative stress (Zik et al., 1998; Lee et al., 2010). These observations indicate that GADs play important roles in growth and development, and stress responses in plants. Contrary to animals and Escherichia coli (Ueno, 2000), GAD proteins in yeast (Coleman et al., 2001) and plants (Baum et al., 1993; Gallego et al., 1995; Turano and Fang, 1998; Zik et al., 1998; Lee et al., 2010) are characterized by the presence of a CaMBD in the proximal C-terminal region. Of the two GAD proteins in rice, OsGAD1 shows the presence of an authentic CaMBD (Akama et al., 2001), suggesting that the CaM-binding property could be isoform-dependent. The maximum activity of plant GADs is observed under acidic conditions and is independent of $\mathrm{Ca}^{2+}$-CaM. However, at neutral $\mathrm{pH}, \mathrm{Ca}^{2+}$-CaM becomes an obligatory requirement for the activity of these proteins (Snedden et al., 1995). Stress-induced increase in GABA levels, attributed to enhanced acidification and increase in $\mathrm{Ca}^{2+}$ levels, leads to $\mathrm{Ca}^{2+}$-CaM-induced dimerization of C-terminus domains that results in activation of GADs (Arazi et al., 1995; Snedden et al., 1995; Baum et al., 1996). Overexpression of petunia $G A D$ gene, that encoded a protein lacking the CaM-binding domain, in transgenic tobacco resulted in severe morphological abnormalities indicating the role of glutamate and GABA in plant growth and development (Baum et al., 1993, 1996). Constitutive overexpression of the truncated $O s G A D 2$, that encoded a protein lacking the C-terminus region, resulted in 40-fold increase in its activity. This experiment is the first evidence of $\mathrm{Ca}^{2+}-\mathrm{CaM}-$ independent activation of GAD enzyme in plants (Akama and Takaiwa, 2007). It is evident that C-terminal domain of OsGAD2 protein is involved in autoinhibition. Although a GAD protein lacking the CaMBD (OsGAD2) has only been reported in rice, these studies suggest that regulation of GADs through $\mathrm{Ca}^{2+}$ CaM-dependent and $\mathrm{Ca}^{2+}-\mathrm{CaM}$-independent pathways may provide greater versatility to plants in their response to different environmental conditions. Genome level surveys in different plant species might shed more light on the presence and roles of CaMBD-lacking GADs in $\mathrm{Ca}^{2+} / \mathrm{CaM}$ signaling pathways.

\section{Implications of CaM in Regulation of Plant Responses to Heavy Metals and Xenobiotic Compounds}

Intensive industrialization and agriculture processes result in the release of toxic heavy metals such as nickel, cobalt, cadmium, copper, lead, chromium, and mercury which degrade the ecosystem and are consistently threatening agricultural production, particularly in the developing countries. Toxic levels of heavy metals in plants adversely affect the protein and enzyme structures through interaction with sulfhydryl groups and disrupt the integrity of PM, thereby, inhibiting different metabolic processes such as photosynthesis and respiration (Ovečka and Takáč, 2014; Emamverdian et al., 2015). Uptake of heavy metal ions in plants is mediated through channel proteins that are localized to PM. These proteins consist of transmembrane domains and a putative cyclic nucleotide monophosphate domain that overlaps with CaMBD at Cterminus (Köhler et al., 1999). Overexpression of an $81 \mathrm{kDa}$
PM-localized protein, NtCBP4, in tobacco conferred higher levels of tolerance to $\mathrm{Ni}^{2+}$ due to reduced uptake of this metal ion (Arazi et al., 1999). NtCBP4 protein is homologous to Arabidopsis cyclic nucleotide gated channel protein CNGC1 and binds to CaM. The transgenic plants, however, showed hypersensitivity to $\mathrm{Pb}^{2+}$ that was attributed to its over accumulation. Subsequent studies revealed that deletion of CaM- and cyclic nucleotide binding domains resulted in abrogation of $\mathrm{Pb}^{2+}$-hypersensitivity, primarily due to attenuation in the uptake of this ion by transgenic plants (Table 1; Sunkar et al., 2000). These studies demonstrate that alteration in CaM-binding property of the channel proteins is a potentially viable strategy for engineering tolerance to toxic metals in crop plants, hence, needs to be explored further.

$\mathrm{Ca}^{2+}$-CaM pathway is also implicated in the regulation of apyrases in plants. These proteins hydrolyze nucleoside diand triphosphates. Hydrolysis of these nucleosides in animals has been demonstrated to be essential for neurotransmission (Todorov et al., 1997) and in prevention of thrombosis (Marcus et al., 1997). In plants, activity of a pea (Pisum sativum) apyrase, PsNTP9, localized to nucleus and also present extracellularly (Thomas et al., 2000), was shown to be enhanced by $\mathrm{Ca}^{2+}$ CaM (Chen and Roux, 1986). Subsequent studies revealed that different isoforms of apyrases in Arabidopsis bind differentially to CaM (Steinebrunner et al., 2000). Of the two different apyrases AtAPY1 and ATAPY2 (A. thaliana apyrase 1 and 2) in Arabidopsis, only the former showed interaction with CaM. The differential regulation of different isoforms by $\mathrm{Ca}^{2+}$ CaM may imply distinct role of these proteins in plants that warrants further elucidation. Overexpression of pea apyrase, besides resulting in enhanced growth and phosphate transport in transgenic plants (Thomas et al., 2000), is also reported to confer higher level of tolerance to different herbicides (Windsor et al., 2003) and toxic concentrations of cyclohexane and plant growth regulators (Thomas et al., 2000; Table 1). How these physiological attributes are modulated through $\mathrm{Ca}^{2+}$ CaM pathway remains unknown and need to be investigated experimentally by overexpressing apyrases that lack different domains.

Exposure to plants to high salt concentration is associated with accumulation of cytotoxic compound methylglyoxal, that is produced as a byproduct of glycolysis metabolism (Yadav et al., 2005). Methylglyoxal, present in low concentration ( $\mu \mathrm{M})$ in all organisms studied (Richard, 1993), is detoxified by the enzymes glyoxalase I (GlyI) and glyoxalase II (GlyII; Mannervik and Ridderström, 1993). Expression of GlyI and GlyII genes in plants is enhanced under different abiotic stress conditions (Kaur et al., 2014a,b and references therein). Overexpression of Gly genes from wheat (TaGlyI), Beta vulgaris (BvM14-GlyI), Brassica juncea (GlyI) and rice (GlyII) has been reported to confer enhanced tolerance to salt-, metal-, osmotic- and oxidative stress in transgenic plants (Singla-Pareek et al., 2003, 2006; Lin et al., 2010; Alvarez Viveros et al., 2013; Wu et al., 2013), implying the role of these genes in stress adaptation.

Deswal and Sopory (1999) demonstrated that activity of GlyI enzyme was stimulated by $\mathrm{CaM}, \mathrm{Ca}^{2+}$ and $\mathrm{Mg}^{2+}$ ions, with CaM-induced increase being additive when both the ions were 
TABLE 1 | Functional characterization of genes encoding different calmodulin (CaM)-binding proteins by transgenic analysis.

\begin{tabular}{|c|c|c|c|c|c|c|}
\hline $\begin{array}{l}\text { S. } \\
\text { No. }\end{array}$ & CaM-binding protein & Source of gene & $\begin{array}{l}\text { Transgenic } \\
\text { host }\end{array}$ & Approach & Effect on stress tolerance & References \\
\hline \multicolumn{7}{|c|}{ CaM-BINDING TRANSCRIPTION FACTORS } \\
\hline 1 & $\begin{array}{l}\text { CaM-binding transcription activator } \\
\text { (CAMTA3)/A. thaliana signal } \\
\text { responsive } 1 \text { (AtSR1) }\end{array}$ & Arabidopsis thaliana & A. thaliana & T-DNA insertion mutants & Increase in tolerance to CS & $\begin{array}{l}\text { Doherty et al., } \\
\text { 2009; Du et al., } \\
2009\end{array}$ \\
\hline 2 & $\begin{array}{l}60 \text { kDa CaM-binding protein } \\
\text { (CBP60g) }\end{array}$ & A. thaliana & A. thaliana & Constitutive overexpression & Enhancement in DS tolerance & Wan et al., 2012 \\
\hline 3 & $\begin{array}{l}\text { CaM-binding trihelix transcription } \\
\text { factor (AtGTL1) }\end{array}$ & A. thaliana & A. thaliana & Loss-of-function mutation & Improved DS tolerance & Yoo et al., 2010 \\
\hline 4 & CaM-binding-GTL1 (PtaGTL1) & $\begin{array}{l}\text { Populus tremula } x \\
\text { Populus alba }\end{array}$ & A. thaliana & Constitutive overexpression & Decline in DS tolerance & Weng et al., 2012 \\
\hline 5 & $\begin{array}{l}25 \text { kDa CaM-binding protein } \\
\text { (AtCAMBP25) }\end{array}$ & A. thaliana & A. thaliana & Constitutive expression & Decrease in OS tolerance & $\begin{array}{l}\text { Perruc et al., } \\
2004\end{array}$ \\
\hline \multirow[t]{2}{*}{6} & CaM-binding WRKY39 (AtWRKY39) & A. thaliana & A. thaliana & wrky39 mutant & Impaired HS tolerance & Li et al., 2010 \\
\hline & & & & Constitutive overexpression & Increase in HS tolerance & Li et al., 2010 \\
\hline \multicolumn{7}{|c|}{ CaM-BINDING KINASES, PHOSPHATASES AND OTHER ENZYMES } \\
\hline 7 & $\begin{array}{l}\mathrm{Ca}^{2+} \text {-dependent CaM receptor-like } \\
\text { kinase (GsCBRLK) }\end{array}$ & Glycine soja & A. thaliana & Constitutive overexpression & $\begin{array}{l}\text { Enhanced tolerance to CS, SS } \\
\text { and OS }\end{array}$ & Yang et al., 2010a \\
\hline 8 & $\begin{array}{l}\mathrm{Ca}^{2+} / \mathrm{CaM} \text {-regulated receptor-like } \\
\text { kinase (AtCRLK1) }\end{array}$ & A. thaliana & A. thaliana & T-DNA knock-out mutation & Increase in CS tolerance & $\begin{array}{l}\text { Yang et al., } \\
2010 b\end{array}$ \\
\hline 9 & $\begin{array}{l}\text { CaM-binding protein kinase } 3 \\
\text { (AtCBK3) }\end{array}$ & A. thaliana & A. thaliana & Constitutive overexpression & Enhanced tolerance to HS & Liu et al., 2008 \\
\hline 10 & $\begin{array}{l}\text { CaM-binding Ser/Thr phosphatase } \\
\text { (AtPP7) }\end{array}$ & A. thaliana & A. thaliana & Constitutive overexpression & Increase in HS tolerance & Liu et al., 2007 \\
\hline 11 & $\begin{array}{l}\text { CaM-binding mitogen-activated } \\
\text { protein kinase phosphatase (NtMKP1) }\end{array}$ & N. tabacum & N. tabacum & Constitutive overexpression & $\begin{array}{l}\text { Reduction in wound-induced } \\
\text { activation of genes }\end{array}$ & $\begin{array}{l}\text { Yamakawa et al., } \\
2004\end{array}$ \\
\hline 12 & CaM-binding MKP1 (OsMKP1) & Oryza sativa & O. sativa & $\begin{array}{l}\text { Retrotransposon } \\
\text { Tos17-mediated } \\
\text { loss-of-function mutation }\end{array}$ & $\begin{array}{l}\text { Constitutive activation of } \\
\text { wound response }\end{array}$ & Katou et al., 2007 \\
\hline \multirow[t]{2}{*}{13} & $\begin{array}{l}\text { Full length CaM-binding protein/cyclic } \\
\text { nucleotide gated channel (NtCBP4) }\end{array}$ & Nicotiana tabacum & N. tabacum & Constitutive overexpression & $\begin{array}{l}\text { Enhanced tolerance to } \mathrm{Ni}^{2+} \\
\text { but hypersensitivity to } \mathrm{Pb}^{2+}\end{array}$ & Arazi et al., 1999 \\
\hline & Truncated NtCBP4 lacking CaMBD & N. tabacum & N. tabacum & Constitutive overexpression & $\begin{array}{l}\text { Abrogation of } \\
\mathrm{Pb}^{2+} \text {-hypersensitivity }\end{array}$ & Arazi et al., 1999 \\
\hline 14 & Apyrase (PsNTP9) & Pisum sativam & A. thaliana & Constitutive overexpression & $\begin{array}{l}\text { Increased tolerance to } \\
\text { cyclohexane and } \\
N^{6} \text {-[2-isopentyl]adenine (2iP) }\end{array}$ & $\begin{array}{l}\text { Windsor et al., } \\
2003\end{array}$ \\
\hline
\end{tabular}

CaMBD, CaM-binding domain; CS, cold stress; DS, drought stress; HS, heat stress; MAPK, mitogen-activated protein kinase; OS, osmotic stress.

present together. However, binding of CaM with GlyI protein in vivo, and regulation of glyoxalase pathway by $\mathrm{Ca}^{2+}-\mathrm{CaM}$ needs to be demonstrated by using BiFC/FRET assays, mutants and pharmacological approaches. Recent studies have revealed up to 11 different Gly genes in rice and A. thaliana (Kaur et al., 2013). Since no information is available on CaMBD(s) in members of GlyI and GlyII families, we carried out in silico analysis of these proteins from rice and Arabidopsis using online tool (http://calcium.uhnres.utoronto.ca/ctdb/ctdb/browse.html). This study revealed the presence of up to three different putative CaMBDs in several members of GlyI and GlyII protein families in Arabidopsis and rice (Table S1). AtGlyI-13.5 and OsGlyI-1 proteins also showed the presence of an unclassified CaMBD and an IQ motif, respectively. Different GlyI genes in rice show differential inducibility under different abiotic stress conditions (Mustafiz et al., 2011). Therefore, specificity of CaM for different Gly proteins need to be investigated for understanding the role of $\mathrm{Ca}^{2+} / \mathrm{CaM}$ pathway in the regulation of these enzymes.

\section{Regulation of Reactive Oxygen Species by CaM}

Production of ROS is one of the major determinants of stressinduced damage to the cells (Mittler, 2002). Hydrogen peroxide $\left(\mathrm{H}_{2} \mathrm{O}_{2}\right)$, one of the ROS, is a secondary signal molecule that constitutes an important component of signal transduction pathways that enable the plants to respond to changes in external stimuli (Del Río, 2015). $\mathrm{H}_{2} \mathrm{O}_{2}$ in plants is generated during photorespiration, mitochondrial electron transport and $\beta$-oxidation of fatty acids (Scandalios et al., 1997), and its intracellular levels are stringently controlled for maintaining homeostasis in the cell. Catalase degrades $\mathrm{H}_{2} \mathrm{O}_{2}$ into water and 
$\mathrm{O}_{2}$, and is one of the critical antioxidant enzymes that protect the cells against ROS-induced damage under stressful conditions. As compared to single isoform in animals, plants contain multiple isoforms of catalases (McClung, 1997; Scandalios et al., 1997). Contrary to bacteria, bovine, human or fungi, plants also contain catalases that are activated after binding to $\mathrm{Ca}^{2+}{ }_{-} \mathrm{CaM}$ (Yang and Poovaiah, 2002b). The CaMBD of Arabidopsis catalase, AtCAT3, is located in the C-terminus amino acid residues 415-451 and is autoinhibitory for its enzyme activity (Yang and Poovaiah, $2002 \mathrm{~b})$. It has been postulated that binding of $\mathrm{Ca}^{2+}-\mathrm{CaM}$ to this domain relieves autoinhibition and makes these proteins catalytically active in response to $\mathrm{Ca}^{2+}$ spike. For studying variability in CaMBDs of different catalases, we carried out multiple sequence alignment that revealed high homology in this region [73.0 and 70.3\% identity of AtCAT3 CaMBD with rice and sorghum (Sorghum bicolor) homologs, respectively] (Figure S1; Table S2), suggesting functional conservation.

$\mathrm{H}_{2} \mathrm{O}_{2}$ is also reported to activate $\mathrm{Ca}^{2+}$-channels (Pei et al., $2000)$, thereby, inducing an increase in the $\left[\mathrm{Ca}^{2+}\right]_{\text {cyt }}$ levels (Price et al., 1994). Paradoxically, the production of $\mathrm{H}_{2} \mathrm{O}_{2}$ from NADPH is catalyzed by NADPH oxidase that requires continuous influx of $\mathrm{Ca}^{2+}$ for its activity (Keller et al., 1998). Furthermore, the activity of NAD kinase that generates the substrate $(\mathrm{NADPH})$ for $\mathrm{NADPH}$ oxidase from $\mathrm{NAD}^{+}$is also modulated through $\mathrm{Ca}^{2+}{ }_{-} \mathrm{CaM}$ (Harding et al., 1997). These observations indicate toward an intricate mechanism of feedback regulation of different enzymes through $\mathrm{Ca}^{2+}$ and $\mathrm{CaM}$ that may enable the plants to maintain $\mathrm{H}_{2} \mathrm{O}_{2}$ homeostasis, thus offering protection against stress-induced damage.

\section{CaM is involved in Modulation of Transcription Factors}

Precise regulation of gene expression is imperative for successful completion of life cycle of an organism and its capability to withstand adverse environmental conditions. Expression of genes is regulated by a battery of transcription factors (TFs) and approximately two- and three-thousand genes encoding these proteins have been identified in human and A. thaliana, respectively (The Arabidopsis Genome Initiative, 2000). Activity of several TFs is modulated by $\mathrm{Ca}^{2+}$ (Bouché et al., 2002), either by direct binding, as for DREAM proteins (Carrión et al., 1999) or through $\mathrm{Ca}^{2+}$-CaM. Modulation of TFs by CaM can either be through direct interaction, as observed for helix-loophelix TFs (Corneliussen et al., 1994) or through the control of kinase-mediated phosphorylation (Corcoran and Means, 2001). The proteins belonging to CaM-binding transcription activator (CAMTA) family of TFs in plants are conserved at structural and sequence levels, suggesting their essential role in the cell (Choi et al., 2005). The expression of different CAMTA genes is induced in response to different environmental cues such as heat stress, light, hormone, and pathogen attack (Yang and Poovaiah, 2002a), implying their role in stress response. Multiple isoforms of CAMTA proteins are reported in plants. Six genes (AtCAMTA16) encoding different proteins have been identified in Arabidopsis (Bouché et al., 2002; Finkler et al., 2007), rice (Choi et al.,
2005), and sorghum (this study; Table S3). CAMTA proteins are characterized by the presence of specific domains that are responsible for nuclear localization (a bipartite signal in the $\mathrm{N}$-terminal), non-sequence-specific DNA-binding domain (TIG domain), protein-protein interaction domain (ankyrin domain) and IQ domain in the C-terminus (Gly ${ }^{872}-\mathrm{Arg}^{889}$; Bouché et al., 2002).

A rice CaM-binding TF, OsCBT, that shows $44.1 \%$ amino acid identity with Arabidopsis AtCAMTA5 (Table S3) was demonstrated to possess two CaMBDs, CaMBD1 (amino acid residues 764-777) and CaMBD2 (amino acid residues 825-845; Figure S2; Table S4; Choi et al., 2005). CaMBD1, consisting of an IQ-motif, binds to $\mathrm{CaM}$ in a $\mathrm{Ca}^{2+}$-independent manner and constitutes the $\mathrm{Ca}^{2+}$-dependent CaM-dissociation domain. On the contrary, interaction of CaMBD2 with $\mathrm{CaM}$ is $\mathrm{Ca}^{2+}$. dependent. Therefore, the presence of these domains enables OsCBT to interact with $\mathrm{CaM}$ in absence as well as presence of $\mathrm{Ca}^{2+}$. OsCBT is localized to nucleus due to the presence of two different nuclear localization signals (NLSs) at both $\mathrm{N}$ terminus (amino acid residues 73-90) and C-terminus (amino acid residues 837-840; Choi et al., 2005). Studies by these authors further revealed that coexpression of OsCaM and OsCBT genes resulted in inhibition of transcriptional activity of the latter, thereby providing evidence for the role of CaM in regulation of gene expression.

In order to understand the significance of CaM-regulation of CAMTA proteins in plants, we retrieved amino acid sequences of these proteins from Arabidopsis, rice, and sorghum genome databases and carried out multiple sequence alignment analysis of CAMBD1 and CAMBD2 (Figure S2; Table S5). This analysis revealed that $\mathrm{Ca}^{2+}$-dependent $\mathrm{CaMBD} 2$ is conserved among these proteins, whereas CaMBD1 is observed only in AtCAMTA5 and 6 in Arabidopsis, and in a single isoform in sorghum (acc. no. XP_002462876.1; Figure S2). It is evident that in contrast to CaMBD1, CaMBD2 appears to be evolutionarily conserved in plant taxa. Conservation of $\mathrm{Ca}^{2+}$-dependent CaMBD (CaMBD2) in plants may be the result of an adaptive strategy to regulate the cellular responses under conditions that lead to an alteration in $\mathrm{Ca}^{2+}$ signal. On the contrary, the presence of $\mathrm{Ca}^{2+}$ dependent CaM-dissociation domain in an isoform-specific manner suggests that different members of CAMTA proteins family may be playing distinct roles in $\mathrm{Ca}^{2+} / \mathrm{CaM}$ pathway, thereby providing versatility to plants in responding to different environmental conditions. We also speculate that since OsCBT shows $98.7 \%$ identity to another CAMTA protein in rice (acc. no. LOC_Os07G30774.1; Table S3), the two may be polymorphic variants of the same protein that needs to be validated by analyzing additional genotypes. Understanding the functional significance of OsCBT polymorphism may reveal novel insights into the role of these proteins in $\mathrm{Ca}^{2+} / \mathrm{CaM}$ signaling pathway.

The C-repeat binding factors or CBF transcription factors, induced rapidly under cold stress, play an important role in acquisition of tolerance to cold stress through regulation of $\sim 100$ other genes (collectively designated as CBF-regulon) that are implicated in cold acclimation (Maruyama et al., 2004). Imposition of cold stress also results in the elevation of $\left[\mathrm{Ca}^{2+}\right]_{\text {cyt }}$ levels due to its release from vacuolar as well as 
extracellular stores (Knight et al., 1996). One of the CAMTA proteins, CAMTA3, in Arabidopsis (also termed as A. thaliana signal responsive 1 or AtSR1) was demonstrated to regulate expression of CBF2 by binding to a conserved DNA-binding motif CM2 or CG-element (vCGCGb) present in the ZAT12 promoter region of the latter (Doherty et al., 2009). These studies established a link between cold-induced increase in intracellular $\mathrm{Ca}^{2+}$, expression of CBF-regulon, and cold tolerance (Table 1). The role of CAMTA TFs in cold stress tolerance of plants is further supported by their localization to nucleus (Bouché et al., 2002) and by the presence of at least one CAMTA3interacting CG-element in the promotor regions of 30 different genes induced in early stage of cold stress (Doherty et al., 2009). CAMTA3 regulates rapid and transient general stress response by binding to a cis-acting element RSRE (rapid stress-response element; CGCGTT; Benn et al., 2014). Though CAMTA protein is constitutively present in the nucleus and binds to DNA even in the absence of CaM (Bouché et al., 2002; Yang and Poovaiah, 2002a), the RSRE-mediated expression of genes is observed only under stress. It has been proposed that RSRE-mediated expression under stress by CAMTA3 may be induced after binding with $\mathrm{Ca}^{2+}{ }_{-} \mathrm{CaM}$ that facilitates interaction of this protein with other TFs, resulting in transcription of stress-responsive genes (Bjornson et al., 2014).

Besides cold stress adaptation, CAMTA3 is also involved in repression of plant immunity since the Arabidopsis plants mutated in CAMTA3 (atsr1) showed enhanced resistance to virulent strain of Pseudomonas syringae. The atsr 1 plants depicted early induction of PR1 (PATHOGENESIS RELATED 1) gene, after $6 \mathrm{~h}$ inoculation of $P$. syringae as compared with $24 \mathrm{~h}$ in wild type plants (Du et al., 2009). Repression of defense response by AtSR1 is attributed to the suppression of EDS1 (ENHANCED DISEASE SUSCEPTIBILITY 1) gene that encodes a positive regulator of salicylic acid synthesis. Du et al. (2009) provided evidence that regulation of EDS1 by AtSR1 protein is through its interaction with CG-element present in the promotor of the former. $\mathrm{Ca}^{2+}$ signaling is crucial for stimulating the production of ROS and NO that lead to the induction of hypersensitive response (Guo et al., 2003; Lecourieux et al., 2006; Ali et al., 2007). However, the uncontrolled defense response also affects the growth of plants adversely (Gurr and Rushton, 2005). By acting as a suppressor of immune response, AtSR 1 may be playing a central role in fine tuning the defense response of plants. Suppression of immune response by AtSR1 is regulated through $\mathrm{Ca}^{2+}$-CaM since deletion of CaMBD from this protein results in failure to suppress plant immunity (Du et al., 2009). The negative regulation of immune response by $\mathrm{Ca}^{2+}$-CaM-AtSR1 complex is proposed to be released through AtSR1-Interacting-Protein1 (SR1-1P1) that binds to AtSR1 and facilitates ubiquitination and degradation of the latter upon pathogen challenge (Zhang et al., 2014). Though AtCaMTA3 is acting as a positive regulator of cold stress tolerance and also as a suppressor of immune response in plants, the underlying mechanism(s) responsible for cross-talk between the two pathways are not understood (Figure 1). Therefore, interaction between the pathogen-induced hyperresponse and cold acclimation needs to be elucidated by studying the kinetics of SR1-1P1 and AtSR1 induction under combined exposure. These studies may lead to an understanding of the different mechanisms that allow plants to maintain a balance between the two responses (Figure 1).

One of the CAMTA proteins in Arabidopsis, CAMTA1, has also been demonstrated to play a role in auxin response (Galon et al., 2010) and drought adaptation (Pandey et al., 2013; Figure 1). Exogenous application of auxin results in enhanced levels of $\left[\mathrm{Ca}^{2+}\right]_{\text {cyt }}$ and induces TFs such as MYB77 that binds to auxin response factor, thereby regulating growth and development processes in plants (Shin et al., 2007; Galon et al., 2010). Galon et al. (2010) observed that expression of several genes $(\sim 17)$, that are otherwise induced by auxin signaling pathways, was upregulated in plants mutated in CAMTA1. On the contrary, expression of genes that are involved in flavonoid biosynthesis and sulfur metabolism pathways was down regulated in CAMTA1 mutants. Expression of CAMTA1 is reported to enhance under different stress conditions (Yang and Poovaiah, 2002a). Therefore, suppression of auxin response could be a crucial factor in maintaining homoeostasis, as inhibition of growth and development under stress may enable the plants to divert resources toward stress adaptation. Although intracellular $\mathrm{Ca}^{2+}$ levels are enhanced in response to both auxin and stress conditions (Galon et al., 2010), the role of $\mathrm{Ca}^{2+} / \mathrm{CaM}$ in CAMTA1-induced inhibition of auxin response has not been demonstrated. Therefore, studies employing mutants, $\mathrm{Ca}^{2+}$ channel blockers and CaM-antagonists are required to provide further insights into the role of $\mathrm{Ca}^{2+} / \mathrm{CaM}$ signaling pathway in CAMTA1-mediated auxin response.

Plants contain another large family of TFs that are characterized by the presence of NAC domain (No Apical Meristem in Petunia; ATAF1, ATAF2, and Cup-Shaped Cotyledon in Arabidopsis), with 100-150 members reported in rice (Nuruzzaman et al., 2010) and foxtail millet (Setaria italica; Puranik et al., 2013). NAC genes have been reported to play a crucial role in stress adaptation since overexpression of one of the genes of this family, SNAC1 (STRESS-RESPONSIVE NAC $1)$, in rice imparted drought tolerance without any associated yield penalty ( $\mathrm{Hu}$ et al., 2006). NAC proteins are characterized by the presence of a conserved N-terminus DNA-binding domain and a C-terminus variable region that is implicated in activation (Tran et al., 2004) as well as repression (Kim et al., 2007) of the transcription. The transcription repressor activity of an Arabidopsis NAC protein (CBNAC) was enhanced after $\mathrm{Ca}^{2+}$-dependent interaction with CaM (Kim et al., 2007; Figure 1). Conserved domain analysis of different NAC proteins of Arabidopsis, carried out in the present study (data not shown), revealed that CaMBD (comprising of amino acid residues 471-512 in CBNAC) is not conserved among different members of this family. The selective presence of CaMBD among NAC proteins suggests that different members of this family are regulated differentially by $\mathrm{CaM}$ and perform distinct regulatory functions. Experimental analysis is required to determine the CaM-binding property of different NAC proteins so that the role of these proteins can be established in $\mathrm{Ca}^{2+} / \mathrm{CaM}$ signal transduction pathway.

$\mathrm{Ca}^{2+} / \mathrm{CaM}$ pathway is also implicated in the regulation of MYB TFs. These proteins regulate several aspects of growth and 


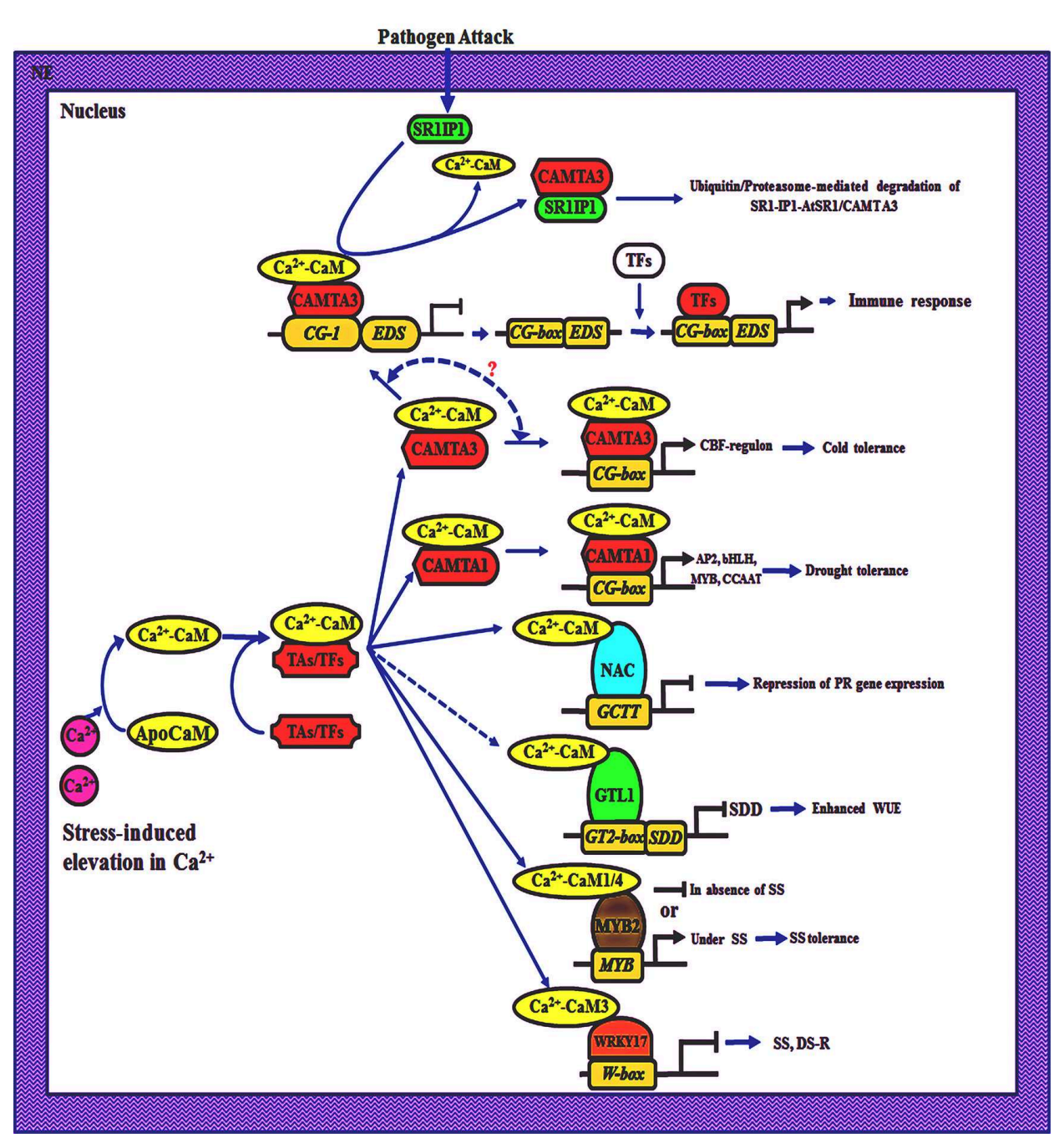

FIGURE 1 | Schematic representation of $\mathrm{Ca}^{2+}$ /calmodulin (CaM)-mediated transcriptional regulation in plants. Plants respond to different hormonal, developmental and environmental cues through transient fluctuations in cytosolic $\mathrm{Ca}^{2+}$ which is detected by CaM, leading to conformational changes in the latter. The $\mathrm{Ca}^{2+}$-loaded CaM $\left(\mathrm{Ca}^{2+}-\mathrm{CaM}\right)$ interacts with transcriptional activators (TAs) such as CaM-binding transcriptional activators (CAMTA) or transcription factors (TFs) such as NAC, MYB, WRKY, GTL1, resulting in repression $(-1)$ or induction $(\rightarrow)$ of the downstream genes. NE, nuclear envelop; SR1IP1, SR1-Interacting-Protein-1; EDS1, Enhanced Disease Susceptibility 1; SDD1, Stomatal Density and Distribution 1; SS, Salt stress; DR, drought stress-regulon; WUE, water use efficiency; PR, Pathogenesis-Related genes.

development such as cell cycle, morphogenesis, and secondary metabolism in plants (Kranz et al., 1998). DNA-binding activity of one of the MYB proteins, AtMYB2, that controls expression of dehydration- and salt stress-responsive genes in Arabidopsis was reported to enhance after interaction with a salt stressinduced isoform of G. max CaM (GmCaM4; Yoo et al., 2005). These authors also observed that $\mathrm{Ca}^{2+}$-dependent interaction of AtMYB2 with GmCaM4 resulted in transcriptional activation of genes of proline biosynthetic pathway leading to an increase in proline accumulation. On the contrary, the activity of AtMYB2 was inhibited by another CaM isoform, GmCAM1, thus, implying differential role of $\mathrm{CaM}$ isoforms in regulation of these TFs. Site-directed mutagenesis, resulting in substitution of $\mathrm{Lys}^{69}$ to $\mathrm{Arg}^{69}$ in CaMBD (amino acid residues 63-82) of
AtMYB2 protein, abrogated the binding with GmCaM1. On the contrary, the interaction of AtMYB2 with GmCaM4 was inhibited only when both $\mathrm{L}^{69}$ and $\mathrm{I}^{78}$ were replaced with Arg (Yoo et al., 2005). These two isoforms have been proposed to play specific roles in plants. The constitutive expression of GmCaM1 maintains the transcription of AtMYB2-regulated genes at basal levels under control conditions. On the other hand, the salt stress-induced accumulation of GmCaM4 protein leads to enhanced expression of genes such as DELTA1-PYRROLINE-5CARBOXYLATE SYNTHASE 1, DEHYDRATION-RESPONSIVE PROTEIN RD22, and ALCOHOL DEHYDROGENASE 1 that encode protective proteins, leading to stress tolerance (Yoo et al., 2005). Role of $\mathrm{GmCaM} 4$ in stress adaptation was also supported by the studies which demonstrated that overexpression of this 
gene resulted in a concomitant increase in stress tolerance of transgenic Arabidopsis plants, whereas overexpression of GmCaM1 had no significant effect. Identification of other members of MYB TF family that are regulated by $\mathrm{Ca}^{2+}{ }_{-} \mathrm{CaM}$ will further enhance our understanding of the role of these proteins in signal transduction pathways responsible for stress adaptation in plants.

The WRKY transcription factors, comprising of 74 members in Arabidopsis, are characterized by the presence of DNAbinding or WRKY domain at $\mathrm{N}$-terminus and $\mathrm{C} 2 \mathrm{H}-\mathrm{C} / \mathrm{H}$ zinc motif (Eulgem et al., 2000). The WRKY domain consists of amino acid residues WRKYGOK, and based on the number of these domains and zinc motifs these TFs are grouped as G1, $\mathrm{G} 2\left(\mathrm{G} 2_{\mathrm{a}+\mathrm{b}} ; \mathrm{G} 2_{\mathrm{c}} ; \mathrm{G} 2_{\mathrm{d}}\right)$ and G3 (Eulgem et al., 2000). One of the group $\mathrm{G} 2 \mathrm{~d}$ members in Arabidopsis, AtWRKY7, is induced by pathogen attack and salicylic acid, and depicts interaction with CaM only in the presence of $\mathrm{Ca}^{2+}$ (Park et al., 2005). The CaMBD $\left({ }^{72}\right.$ VAVNSFKKVISLLGRSR $\left.{ }^{88}\right)$ present in the Cterminus of AtWRKY7 is distinct from the classical CAMBDs described until now and is conserved in several group $\mathrm{G} 2 \mathrm{~d}$ members (WRKY11, 15, 17, 21, 39, and 74; Park et al., 2005). Exposure to pathogens and salicylic acid also results in $\mathrm{Ca}^{2+}$ spike (Du et al., 2009). Therefore, the possibility that AtWRKY7 may be regulated through $\mathrm{Ca}^{2+}{ }_{-} \mathrm{CaM}$ pathway cannot be ruled out and needs to be demonstrated experimentally. Until recently, the WRKY TFs were implicated in the modulation of immune response, and growth and development of plants (Rushton et al., 2010). Recent studies have shown that these proteins also play an important role in abiotic stress adaptation (Tripathi et al., 2014 and references therein). A WRKY gene, GhWRKY17, in cotton has been implicated in drought and salt tolerance through regulation of ROS production and $\mathrm{ABA}$ signaling pathway. In silico analysis of amino acid sequences revealed that AtWRKY17 is $42.7 \%$ identical to GhWRKY17 but CaMBDs of these proteins share $78 \%$ identity, signifying functional conservation (Yan et al., 2014). However, the role of $\mathrm{Ca}^{2+}$-CaM pathway in regulation of activity of the GhWRKY17 and implications thereof on stress tolerance of plants are still a matter of conjecture and warrant further investigations (Figure 1).

Another plant-specific family of TFs that bind to CaM consists of CBP60 proteins (Bouché et al., 2005). One of the members of this family, CBP60g, in Arabidopsis showed $\mathrm{Ca}^{2+}$-dependent interaction with CaM (Wang et al., 2009b). Though CBP60g, localized to nucleus, is implicated in defense signaling, recent studies have shown a role of this protein in abiotic stress tolerance also (Table 1). Wan et al. (2012) observed that CBP60goverexpressing transgenic Arabidopsis plants, besides exhibiting higher levels of salicylic acid and enhanced resistance to $P$. syringae, also demonstrated increased tolerance to drought stress. These authors also reported higher sensitivity of the transgenic lines to ABA. However, the molecular mechanism(s) responsible for CBP60g-induced drought tolerance in the transgenic plants and the role of $\mathrm{Ca}^{2+} / \mathrm{CaM}$ in its regulation are not known and need to be explored further. Apart from that, whether the ABAhypersensitivity of transgenic plants was due to an increase in endogenous ABA or because of changes in the expression of proteins of $\mathrm{ABA}$ signaling pathway also needs to be addressed for deciphering the molecular basis of these observations. To conclude, these studies suggest that regulation of different TFs through $\mathrm{Ca}^{2+} / \mathrm{CaM}$ pathway is a crucial aspect of abiotic stress response in plants and unraveling of these mechanisms may lead to novel strategies for developing stress tolerance in different crops.

One of the most desirable features for drought stress adaptation in plants is to maximize water use efficiency (WUE; Nobel, 1999). Of the several variables affecting WUE, stomatal aperture and density, which regulate the rate of transpiration (Chaerle et al., 2005), are affected by several environmental factors such as light, temperature, $\mathrm{CO}_{2}$, and water availability. The family of trihelix transcription factors or GT factors, comprising of 30 and 31 members in Arabidopsis and rice, respectively (Riechmann et al., 2000; Wang et al., 2014b), is characterized by the presence of highly conserved trihelix domain and binds specifically to the GT-elements (Dehesh et al., 1992; Zhou, 1999). The GT factors, divided into five different groups viz., SIP1, SH4, GT $\gamma$, GT-1, and GT-2 in Arabidopsis, are implicated in the regulation of different developmental processes and responses to abiotic and biotic stresses (Wang et al., 2014b). Recent studies have demonstrated that one of the members of this family, GTL1 (GT-2 LIKE 1), acts as a negative regulator of WUE since loss of function mutation in this gene in Arabidopsis resulted in enhanced tolerance to water stress (Table 1; Yoo et al., 2010). On the contrary, overexpression of its poplar (Populus tremula $\times$ Populus alba) homolog PtaGTL1 suppressed the drought tolerance (Weng et al., 2012; Table 1). The negative regulation of WUE by GTL1 protein is mediated through suppression of SDD1 (STOMATAL DENSITY AND DISTRIBUTION 1) following its binding to GT2-box (GGAAT) in the promoter of the latter (Figure 1). SDD1 encodes a subtilisin-like protease and represses the stomatal development through activation of genes encoding ER (ERECTA) and TMM (Too Many Mouths) proteins (von Groll et al., 2002; Shpak et al., 2005), resulting in a decrease in stomatal density and consequently enhancement in WUE. PtaGTL1 has been recently demonstrated to interact with $\mathrm{CaM}$ in a $\mathrm{Ca}^{2+}$-dependent manner through the C-terminus amino acid residues 528-551 and 555575 (Weng et al., 2012), suggesting a role for $\mathrm{Ca}^{2+}{ }_{-} \mathrm{CaM}$ pathway in the regulation of this protein. However, effect of $\mathrm{Ca}^{2+}-\mathrm{CaM}$ on interaction of GTL1 protein with SDD1 promoter, imperative for understanding the regulation of GTL1 through $\mathrm{Ca}^{2+}$-CaM pathway under stress conditions, has not been demonstrated in vitro or in vivo and awaits validation. GT-1 cis-element (GAAAAA) that binds to Arabidopsis GT-1-like transcription factor, AtGT-3b, is also observed in the promoter region of a soybean CaM gene, SCaM-4 (Park et al., 2004). These authors observed that there was a concomitant and rapid increase in mRNA transcripts of SCaM-4 and AtGT-3b after pathogen attack and $\mathrm{NaCl}$ treatment, the induction of former being attributed to the presence of GT-1 cis-element. Regulation of SCaM-4 expression through interaction between GT-1 cis-element and GTL-1 transcription factor (Park et al., 2004) points toward a complex feedback loop that may allow precise control over $\mathrm{Ca}^{2+}$-CaM-mediated stress response(s). However, in silico and empirical analysis of promoter regions of different $C a M$ genes 
for the presence of GT-1 elements and their regulation by GTL TFs in different plant species is required to validate this speculation.

Negative regulation of stress tolerance is also observed for a plant-specific gene encoding a $25 \mathrm{kDa}$ protein, AtCAMBP25, in Arabidopsis that shows low affinity interaction with CaM in the presence of $\mathrm{Ca}^{2+}$ (Perruc et al., 2004). Interaction of AtCAMBP25 with CaM appears to be isoform-specific since it showed binding to typical CaM, AtCaM1, but not to the less conserved form, AtCaM8. AtCAMBP25 is localized to nucleus but its role in transcription is yet to be demonstrated. Although mRNA transcripts corresponding to AtCAMBP25 showed rapid accumulation under different stress conditions, constitutive expression of this gene in transgenic lines, however, resulted in hypersensitivity to salt- and osmotic stress (Perruc et al., 2004). By virtue of being a negative regulator, it is likely that AtCAMBP25 is involved in the maintenance of homeostasis under salt- and osmotic stress conditions (Table 1). Also, the isoform-specific interaction of $\mathrm{CaM}$ with this protein may enable the plants to fine tune their response in a stress-specific manner.

\section{Implications of $\mathrm{Ca}^{2+}-\mathrm{CaM}$ in Signal Transduction through Modulation of Stress-regulated Kinases}

Transduction of signal through phosphorylation and dephosphorylation, mediated by kinases and phosphatases, respectively, allows the cells to respond and adapt to the environmental changes (Charpenteau et al., 2004). CaM regulates the activity of several kinases in plants, and genes for these proteins have been cloned and characterized in several plant species (Zhang and Lu, 2003 and references therein). The characteristic features of different CaM-binding kinases (CBKs) include the presence of CaMBD, variable $\mathrm{N}$ - and C-terminal domains, and a protein kinase catalytic domain (Zhang and Lu, 2003). Expression of several CBK genes is modulated differentially by different stressors and phytohormones, suggesting their role in abiotic stress response in plants. Hua et al. (2004) reported significant increase in mRNA transcript levels of NtCBK2 in tobacco in response to salt stress and gibberellic acid, whereas, auxin, ABA, heat-, cold-, and osmotic stress had no significant effect. These authors attributed the salt stress-induced increase in the expression of $N t C B K 2$ to a decrease in osmotic potential, which appears unlikely since expression of this gene was unaltered by polyethylene glycol in the same study. Therefore, it is likely that NtCBK2 plays a role in signal transduction specifically under salt stress.

The substrate phosphorylation activity of $\mathrm{NtCBK} 2$, and autophosphorylation activity of Arabidopsis CBK, AtCBK1, were enhanced several folds after binding to $\mathrm{Ca}^{2+}$-CaM (Hua et al., 2003; Xie et al., 2003; Zhang and Lu, 2003; Ma et al., 2004). On the contrary, the autophosphorylation activity of lily (Lilium longiflorum) and tobacco CBKs was downregulated by CaM (Liu et al., 1998; Sathyanarayanan et al., 2001). It is evident that $\mathrm{CaM}$ acts as both negative and positive regulator of $\mathrm{CBK}$ activity in plants. Further, it was observed that CaM had no effect on autophosphorylation activity of maize (Zea mays) CBK (ZmCaMK) but its substrate phosphorylation activity showed obligated requirement for $\mathrm{Ca}^{2+}$-CaM (Pandey and Sopory, 1998, 2001) suggesting that different activities of the same protein can also be affected differently by CaM. The auto- and substrate phosphorylation activities of rice CBK (OsCBK), despite its higher affinity for $\mathrm{CaM}$, are not regulated through $\mathrm{Ca}^{2+}-\mathrm{CaM}$ (Zhang et al., 2002), indicating that CaM might also be involved in modulation of these proteins through other mechanisms that are yet to be identified. Species-dependent differential regulation of CBKs by CaM signifies diversity in the perception of signals and their transduction in response to different stimuli in plant taxa.

A large family of kinases belonging to receptor-like serine/threonine kinases (RLKs), with at least 600 RLK homologs predicted in Arabidopsis (Hardie, 1999), is also reported in plants. Majority (75\%) of the RLKs are localized to PM with the remaining $(25 \%)$ present in the cytoplasm. The cytoplasmicand PM-localized RLKs also differ in their domain architecture, with the former containing only the kinase domain (Yang et al., 2004), whereas the latter also show the presence of additional extracellular ligand-binding- and membrane spanning domains (Torii, 2000). These proteins enable the plants to respond to external cues through signal transduction by recognition of extracellular signals, followed by autophosphorylation on the cytoplasmic kinase domain (Stone and Walker, 1995). Members of both PM- and cytoplasm-localized RLK families are reported to interact with $\mathrm{CaM}$ and have been implicated in stress adaptation response. The transcript level of CRCK1 that encodes CaM-binding receptor-like cytoplasmic kinase (CRCK1), a cytoplasmic RLK in Arabidopsis, was upregulated by salt- and cold stress, $\mathrm{ABA}$, and $\mathrm{H}_{2} \mathrm{O}_{2}$ treatments (Yang et al., 2004). The substrate- and autophosphorylation activities of CRCK1 were enhanced following $\mathrm{Ca}^{2+}$-dependent interaction with $\mathrm{CaM}$ through amino acid residues 160-183. The kinase activities of PM-localized RLKs of Glycine soja (GsCBLRK; Yang et al., 2010b) and Arabidopsis CRLK1 (Yang et al., 2010a), implicated in saltand cold stress tolerance, respectively, are also regulated through $\mathrm{Ca}^{2+}$-dependent interaction with CaM (Table 1). Compared with a single CaMBD in GsCBLRK, two CaMBDs (CaMBD1 at N-terminus amino acid residues 30-49 and CaMBD2 at C-terminus amino acid residues 369-390) are observed in CRLK1, suggesting that besides kinase activity, CaM may also be regulating other functions of this protein. This speculation is also supported by the fact that autophosphorylation activity of another PM-localized RLK, AtCaMRLK, is not affected by its interaction with $\mathrm{Ca}^{2+}{ }_{-} \mathrm{CaM}$ (Charpenteau et al., 2004). Though dynamics of interaction of GsCBLRK and CRLK1 with CaM has not been investigated, it is likely that difference in the number of CAMBDs in these two proteins results in differential affinity with CaM that may be critical for regulating their activities differentially. Variability in regulation of different activities of plant CBKs by CaM signify evolutionary divergence and is possibly the result of myriad adaptive processes operating under diverse environmental conditions that enable the plants to respond in a stimulus-specific manner. 
Growth and development in plants, and their responses to stressful conditions are also modulated through mitogenactivated protein kinases (MAPKs), a different class of kinases that have been reviewed earlier (Pedley and Martin, 2005). The MAPKs are activated and inactivated through phosphorylation and dephosphorylation by MAPK kinase (MEK) and MAPK phosphatases (MKPs), respectively (Katou et al., 2007). Regulation of MKPs through CaM is a feature unique to plants and constitutes an important regulatory point in signal transduction (Katou et al., 2007). Genes coding for MKPs have been cloned and characterized from diverse plant species such as rice (OsMKP1; Katou et al., 2007), Arabidopsis (AtMKP1; Lee et al., 2008), wheat (TMKP1; Ghorbel et al., 2015), and tobacco (NtMKP1; Yamakawa et al., 2004; Figure S3). These proteins have been demonstrated to interact with CaM in a $\mathrm{Ca}^{2+}$-dependent manner. Despite high similarity in their amino acid sequences, these proteins show variability in the number of CaMBDs and their affinities toward CaM. Only a single putative CaMBD is observed in NtMKP1 and OsMKP1, compared with two in AtMKP1 (CaMBD1 at amino acid residues 445-469 and CaMBD2 at amino acid residues 669-692) and TMKP1 (CaMBD1 at amino acid residues 398-449 and CaMBD2 at amino acid residues 618-669; Lee et al., 2008; Ghorbel et al., 2015). In AtMKP1, the interaction of CaM was reported to be stronger with CaMBD2 as compared to CaMBD1. In silico analysis of different MKP1 proteins revealed that as compared to $40.7-59.8 \%$ in dicots, identity among monocots ranged between 68.6 and $80.5 \%$, suggesting higher level of conservation in the latter (Table S6). The CAMBD2 in one of the maize MKP1 isoforms (ZmMKP1.2) showed less conservation as compared to CAMBD1 (Table S7). Recent studies demonstrated that deletion of the two CaMBDs ( amino acid residues 398-449 and 618-669) from TMKP1, an ortholog of AtMKP1, resulted in a 4 -fold increase in phosphatase activity of this protein (Ghorbel et al., 2015), suggesting an autoinhibitory role of these domains. Contrary to AtMKP1, which showed enhanced phosphatase activity following interaction with $\mathrm{Ca}^{2+}$-CaM (Lee et al., 2008), the effect of $\mathrm{Ca}^{2+}{ }_{-} \mathrm{CaM}$ on activity of TMKP1 was cofactor-dependent. The phosphatase activity of TMKP1 was regulated positively by $\mathrm{Ca}^{2+}-\mathrm{CaM}$ in the presence of $\mathrm{Mn}^{2+}$ or $\mathrm{Mg}^{2+}$, whereas interaction with $\mathrm{Ca}^{2+}-\mathrm{CaM}$ in the absence of these metal ions abrogated the enzyme activity (Ghorbel et al., 2015). However, $\mathrm{Ca}^{2+}{ }_{-} \mathrm{CaM}$ had no significant effect on phosphatase activity of the protein that lacked C-terminus amino acid residues. The divergence in CaMBDs and their differential affinity toward $\mathrm{Ca}^{2+}{ }_{-} \mathrm{CaM}$ may allow the plants to respond in a signal-specific manner, suggesting distinct regulatory functions of these proteins in different species. The MKPs are also proposed to act as negative regulators of defense response, as overexpression of NtMKP1 was reported to result in the suppression of kinase activity of several MAPKs that are induced in defense and wound responses (Yamakawa et al., 2004; Table 1). These observations indicate that $\mathrm{Ca}^{2+}-\mathrm{CaM}$-regulated MKPs may constitute a crucial link between $\mathrm{Ca}^{2+}$ signaling and MAPK signaling pathways, enabling the plants to maintain homeostasis under biotic and abiotic stress conditions.

\section{Regulation of Heat Shock Response through $\mathrm{Ca}^{2+} / \mathrm{CaM}$ Signal Transduction Pathway}

Global warming is projected to result in an increase in average temperature (Angilletta, 2009), implying that heat stress may become one of the major limiting factors for crop productivity. Recent studies suggest that yields of rice decline by 10 percent for every $1^{\circ} \mathrm{C}$ increase over mean minimum temperature during the growing season (Peng et al., 2004). Imposition of heat stress results in oxidative damage to cell wall, protein misfolding and denaturation or aggregation at cellular levels (Wang et al., 2004). Understanding the heat stress response in plants is, therefore, imperative for developing crops that are tolerant to high temperature stress. The plants, in general, respond to heat stress by selective repression and induction of genes. Synthesis of heat shock proteins (HSPs) is one of the protective strategies that enable the plants to cope with heat stress. The HSPs act as chaperones, prevent aggregation and recycle the aggregated proteins (Wang et al., 2004; Yamada et al., 2007). Plant HSPs are categorized into different categories viz., small HSPs or sHSPs (12-40 kDa), HSP60 (chaperonin), HSP70, HSP90 and HSP100 (Wang et al., 2004 and references therein). The promoter regions of HSP genes consist of heat shock elements (HSEs; 5'-AGAAnnTTCT-3'), that are recognized by heat shock factors (HSFs) which regulate the expression of these genes (Baniwal et al., 2004; Gao et al., 2008). As compared to other eukaryotes, the number of genes encoding HSFs in plants is substantially higher, with 21 and 25 genes reported in Arabidopsis and rice, respectively (Nover et al., 2001; Wang et al., 2009a).

Imposition of heat stress leads to elevation in $\left[\mathrm{Ca}^{2+}\right]_{c y t}$, and $\mathrm{Ca}^{2+} / \mathrm{CaM}$ signal transduction pathway plays a crucial role in regulating the response of plants to thermal stress (Gong et al., 1998; Liu et al., 2003; Wu et al., 2012). Changes in PM fluidity in response to heat shock result in transduction of signal through cytoskeleton, $\mathrm{Ca}^{2+}$ signatures and CDPKs, followed by an activation of mitogen-activated protein kinases (MAPKs; Sangwan et al., 2002). $\mathrm{Ca}^{2+}$ has also been implicated in increased DNA-binding activity of HSFs through direct interaction (Mosser et al., 1990; Li et al., 2004). These studies, therefore, point toward involvement of $\mathrm{Ca}^{2+}$ in multiple regulatory pathways for controlling the heat shock response in plants. The role of $\mathrm{Ca}^{2+}$ in heat shock response has been further validated by the use of $\mathrm{Ca}^{2+}$-channel blockers, which provided evidence in favor of heat stress-induced influx of $\mathrm{Ca}^{2+}$ from the apoplast (Bush, 1995; Liu et al., 2003; Wu et al., 2012).

In the absence of heat stress, HSPs in the cell are maintained at basal levels through repression of transcription of genes. Heat stress-induced increase in $\left[\mathrm{Ca}^{2+}\right]_{\text {cyt }}$ in plants, reported to occur within 4 and $7 \mathrm{~min}$ in wheat and rice, respectively, precedes the induction of CaM genes (Liu et al., 2003; Wu et al., 2012), followed by transcriptional activation of genes that encode different HSPs. These studies, therefore, point toward the role of $\mathrm{Ca}^{2+} / \mathrm{CaM}$ pathway in the regulation of HSPs. Wu et al. (2012) recently reported that heat stress-induced increase 
in $\left[\mathrm{Ca}^{2+}\right]_{\mathrm{cyt}}$, and expression of OsCaM1-1 and OsHSP17 in rice was abrogated by $\mathrm{CaM}$ antagonists, chlorpromazine and trifluoperazine. Although, this aspect needs to be validated independently, these findings suggest that $\mathrm{Ca}^{2+}$ homeostasis and expression of $\mathrm{CaM}$ genes may be under the control of feedback regulation (Figure 2).

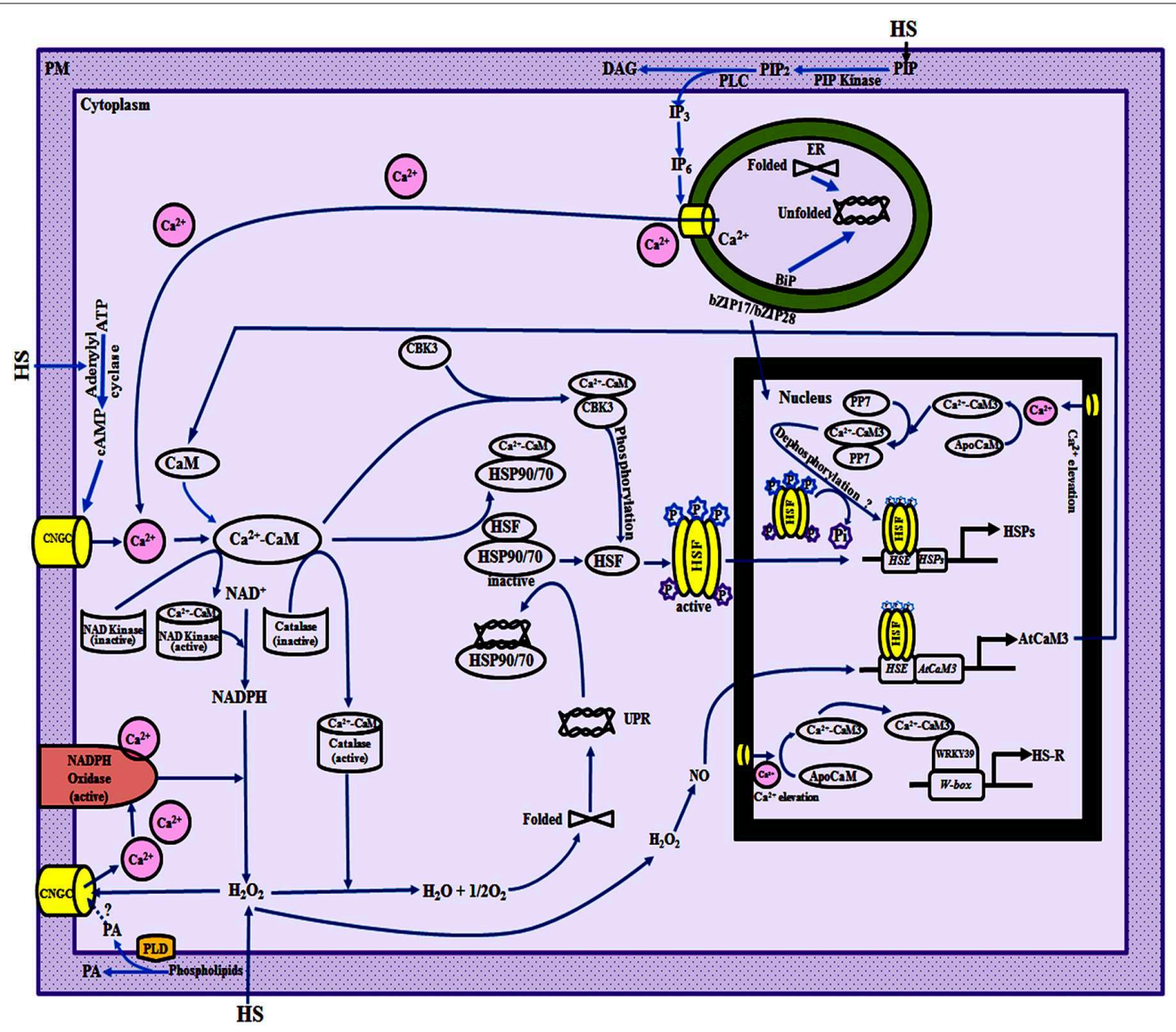

FIGURE 2 | A model illustrating the role of $\mathrm{Ca}^{2+} /$ calmodulin (CaM) in regulation of heat shock response and $\mathrm{H}_{2} \mathrm{O}_{2}$ homeostasis in plants. Changes in plasma membrane (PM) fluidity due to heat stress result in activation of phospholipase D (PLD) and phosphatidylinositol-4-phosphate 5-kinase (PIP kinase), and consequently the accumulation of various lipid signaling molecules such as phosphatidic acid (PA) and phosphatidylinositol-4, 5-bisphosphate (PIP ${ }_{2}$; Mishkind et al., 2009). Thermal stress also activates phospholipase $C$ which converts $\mathrm{PIP}_{2}$ into diacyl glycerol $(\mathrm{DAG})$ and $\mathrm{D}$-myo-inositol-1,4,5-trisphosphate $\left(\mathrm{IP}_{3}\right)$. IP $\mathrm{P}_{3}$ may be phosphorylated and converted into $\mathrm{IP}_{6}$ that interacts with endoplasmic reticulum (ER)-localized $\mathrm{Ca}^{2+}$-channels thus resulting in release of $\mathrm{Ca}^{2+}$ from intracellular stores (Mishkind et al., 2009; Mittler et al., 2012). Rapid influx of extracellular $\mathrm{Ca}^{2+}$ in the cell can also occur due to temperature-induced activation of the PM-localized cyclic nucleotide gated channels (CNGCs) which are non-selective inward cation channels. The CNGC may be activated by heat stress-induced rapid burst in $\mathrm{H}_{2} \mathrm{O}_{2}$ levels (Pei et al., 2000) by cyclic adenosine monophosphate (cAMP) that is produced by heat stress-activated adenylyl cyclase (Köhler et al., 1999) and/or by PA (Mittler et al., 2012). The thermal stress-induced increase in $\left[\mathrm{Ca}^{2+}\right]_{\text {cyt }}$ leads to conversion of ApoCaM to $\mathrm{Ca}^{2+}$-CaM. The expression of HSP genes is repressed in the absence of heat stress which is proposed to be due to interaction of heat shock factors (HSFs) with HSP90 (Zou et al., 1998) and/or HSP70 (Sun et al., 2000). The $\mathrm{Ca}^{2+}-\mathrm{CaM}$ and the denatured proteins, produced as a result of unfolded protein response (UPR) due to reactive oxygen species (ROS)-mediated oxidation, bind to HSP70/HSP90, thereby releasing the HSFs (Yamada and Nishimura, 2008; Virdi et al., 2009, 2011). $\mathrm{H}_{2} \mathrm{O}_{2}$ acts upstream of NO which regulates the expression of AtCaM3 through modulation of the binding of HSF to the heat shock elements (HSEs; Wang et al., 2014a). The temperature-induced increase in NO leads to enhanced levels of $A t C a M 3$, that then binds to $\mathrm{Ca}^{2+}$ and activates the protein kinase AtCBK3 (Arabidopsis thaliana Ca ${ }^{2+}-C_{-}$aM-binding Kinase 3 ), resulting in phosphorylation and trimerization of HSFs which are then translocated to the nucleus (Queitsch et al., 2000). The interaction of activated HSFs with HSEs leads to synthesis of HSPs. Dephosphorylation of the HSFs at selected amino acid residues by a nuclear-localized $\mathrm{Ca}^{2+}$-CaM-binding phosphatase (PP7) may lead to continuous activation of heat shock-regulon (HSR) but the precise mechanism is still not understood. The heat shock response through $\mathrm{Ca}^{2+}-\mathrm{CaM}$-mediated regulation of WRKY transcription factors appears to be independent of HSF-mediated pathway. The WRKY39, after binding to $\mathrm{Ca}^{2+}-\mathrm{CaM}$, interacts with the W-box elements present in the upstream promotor regions of different genes involved in thermotolerance. The ER also plays a critical role in thermal adaptation through UPR-induced release of ER membrane-tethered transcription factors such as bZIP17/bZIP28/bZIP60, which after release are translocated to the nucleus and activate the transcription of genes encoding ER-chaperones and brassinosteroid-signaling pathway related genes (Che et al., 2010; Deng et al., 2011). The intracellular levels of $\mathrm{H}_{2} \mathrm{O}_{2}$ under stress also appear to be maintained through $\mathrm{Ca}^{2+}$-CaM (Wang et al., 2014a). The $\mathrm{H}_{2} \mathrm{O}_{2}$-induced activation of CNGCs (Pei et al., 2000) results in an increase in the $\left[\mathrm{Ca}^{2+}\right]_{\mathrm{cyt}}$ (Price et al., 1994) that further activates NADPH oxidase that converts NADPH to $\mathrm{H}_{2} \mathrm{O}_{2}\left(\mathrm{Keller}\right.$ et al., 1998). The conversion of NAD ${ }^{+}$to $\mathrm{NADPH}$ is catalyzed by NAD kinase that is also modulated through $\mathrm{Ca}^{2+}{ }_{-} \mathrm{CaM}$ (Harding et al., 1997). These observations, therefore, suggest the presence of an intricate feedback regulation through $\mathrm{Ca}^{2+} / \mathrm{CaM}$ pathway which allows the plants to maintain $\mathrm{H}_{2} \mathrm{O}_{2}$ homeostasis. BiP, binding immunoglobulin protein; ER, endoplasmic reticulum; HS, heat stress; NE, nuclear envelop; PM, plasma membrane. 
Recent studies in Arabidopsis have provided evidence that $\mathrm{H}_{2} \mathrm{O}_{2}$ acts upstream of $\mathrm{NO}$ (Wang et al., 2014a). NO regulates the expression of AtCaM3 and functions upstream to $\mathrm{Ca}^{2+}$ $\mathrm{CaM}$ in the signal transduction pathway under heat stress (Xuan et al., 2010). The heat stress-induced increase in NO leads to enhanced levels of AtCaM3 protein that then binds to protein kinase AtCBK3 in the presence of $\mathrm{Ca}^{2+}$ (Liu et al., 2008), leading to phosphorylation of HSFs (Figure 2). The phosphorylated HSFs, after interaction with HSEs, activate the expression of HSP genes resulting in thermotolerance in plants (Queitsch et al., 2000). In further support for the role of $A t C B K 3$ in heat stress adaptation, Liu et al. (2008) observed that $c b k 3$ mutants of Arabidopsis exhibited reduced thermotolerance and overexpression of $A t C B K 3$ rescued the mutant plants (Table 1). Another likely mechanism by which CaM regulates heat shock response in plants is through regulation of protein phosphatases. The protein phosphatase AtPP7 in Arabidopsis exhibits $\mathrm{Ca}^{2+}$ dependent binding to CaM, and mutation in AtPP7 resulted in decreased thermotolerance (Kutuzov et al., 2001; Liu et al., 2007; Table 1). Compared with cytosolic localization of AtCBK3 protein (Liu et al., 2008), the nuclear localization of AtPP7 (Liu et al., 2007) suggests that the latter might be activating the HSFs through its phosphatase activity as HSFs are reported to show enhanced transcriptional activity after dephosphorylation at some sites (Høj and Jakobsen, 1994).

Heat shock response in plants also appears to be regulated by CaM through interaction with HSPs such as HSP70 (Sun et al., 2000) and HSP90 (Virdi et al., 2009, 2011). The HSP90 (Zou et al., 1998) and HSP70 (Sun et al., 2000) have been proposed to act as repressors of HSFs in the absence of heat stress. It has been proposed that denatured proteins, produced as a result of unfolded protein response under heat stress, bind to HSP70/HSP90, thereby releasing the HSF that undergoes trimerization, phosphorylation, and nuclear localization leading to the transcription of genes encoding HSPs (Reindl et al., 1997; Yamada and Nishimura, 2008). Studies in our lab demonstrated that sorghum HSP90, SbHSP90, binds to CaM in a $\mathrm{Ca}^{2+}$. dependent manner (Virdi et al., 2009). It was also observed that the steady state levels of SbHSP90 are regulated through $\mathrm{Ca}^{2+} / \mathrm{CaM}$ pathway since the heat stress-induced increase in HSP90 levels was abrogated in the presence of exogenous $\mathrm{Ca}^{2+}$ channel blockers and CaM-antagonists (Virdi et al., 2011). On the basis of these observations, we proposed that in addition to denatured proteins, as suggested by Yamada and Nishimura (2008), dissociation of HSP90-HSF complex might also involve interaction of $\mathrm{Ca}^{2+}{ }_{-} \mathrm{CaM}$ with HSP90, thereby releasing the HSF to activate the transcription of HSP genes (Virdi et al., 2011). The role of HSP90 as a natural inhibitor of HSF is also supported by studies in Arabidopsis (Yamada et al., 2007) and sorghum (Virdi et al., 2011) where expression of HSP genes was shown to be enhanced by exogenous application of a specific inhibitor of HSP90, geldanamycin, even in the absence of heat shock. Further evidence for validation of the proposed model was also provided by recent studies that reported enhanced expression of $A t C B K 3$, AtPP7, AtHSF, and AtHSP genes in absence of heat stress in the transgenic Arabidopsis that overexpressed OsCaM1-1 (Wu et al., 2012). On the contrary, overexpression of AtHSP90.3 lowered the expression of AtHsfA1d, AtHsfA7a, AtHsfB1, AtHsp101, and AtHsp 17, leading to impaired thermotolerance of transgenic Arabidopsis (Xu et al., 2010). Therefore, regulation of heat shock response in plants by $\mathrm{CaM}$ through multiple pathways may ensure redundancy and enable them to cope up with thermal stress (Figure 2).

In addition to HSPs, plants are also reported to express heatspecific isoforms of FK506-binding proteins, FKBPs, which show peptidyl prolyl cis-trans isomerase activity (Schreiber, 1991). In plants, the multi-domain FKBPs, such as FKBP62, FKBP73, and FKBP77, are characterized by the presence of FKBP domains at N-termini, and CaM-binding and tetratricopeptide repeat domains at C-termini. Though wFKBP73 and wFKBP77 in wheat have been implicated in assembly of functional glucocorticoid complex with p23 and HSP90 (Owens-Grillo et al., 1996; Pratt and Toft, 1997), the implication of CaM in regulation of these proteins is still a matter of speculation and awaits validation. One of the FKBPs in Arabidopsis, AtFKBP62 or ROF1, is heat-inducible and forms a complex with HSP90, which is then translocated from cytosol to nucleus following exposure to thermal stress (Meiri and Breiman, 2009). The heat shock-induced localization of ROF1-HSP90 in the nucleus takes place as a result of interaction of transcription factor HSFA2 with HSP90 in this complex, leading to synthesis of sHSPs and development of thermotolerance. The role of CaM, if any, in the AtFKBP62-mediated stabilization of HSFA2 and its localization to nucleus, is not understood yet and needs further investigations.

\section{Concluding Remarks and Future Directions}

Modulation of intracellular $\mathrm{Ca}^{2+}$ levels in response to unfavorable conditions is one of the important components of signaling pathways that allow plants to adapt to changing environmental conditions. Of the various $\mathrm{Ca}^{2+}$ sensors, CaM is one of the most well-characterized proteins that decodes $\mathrm{Ca}^{2+}$ signals and regulates activities of diverse proteins. Approximately, 3\% of the proteome in Arabidopsis has been reported to be involved in $\mathrm{Ca}^{2+}$ signaling (Reddy et al., 2011). In recent years, considerable progress has been made in our understanding of the role of CaM in regulating different cellular processes in plants. These studies have resulted in the identification and characterization of various proteins that are regulated by CaM. CaM not only acts as a sensor of $\mathrm{Ca}^{2+}$ but also regulates its intracellular levels by modulating the activity of $\mathrm{Ca}^{2+}$-ATPases. Detailed investigations into the specificity of different $\mathrm{CaM}$ isoforms for different $\mathrm{Ca}^{2+}$ pumps may reveal the role of these interactions in generating stimulusspecific signals. In addition to $\mathrm{Ca}^{2+}$ transport, CaM also affects uptake of heavy metal ions through modulation of channel proteins such as NtCBP4. Engineering of these proteins offers a promising alternative for developing transgenic plants that are able to tolerate toxic levels of heavy metal ions. Further, how CaM regulates activities of apyrases and Gly proteins, that confer tolerance to xenobiotic compounds, is still a matter of speculation. Understanding the physiological implications of interaction of CaM with apyrases and Gly enzymes may unravel 
strategies for enhancing stress tolerance in crops by transgenic technologies (Table 1).

Production of ROS under stress conditions is one of the important factors that cause damage to cellular components. Relieving autoinhibition of catalase by $\mathrm{Ca}^{2+}-\mathrm{CaM}$, and regulation of NADPH oxidase and NAD kinase through $\mathrm{Ca}^{2+} / \mathrm{CaM}$ signaling pathway are indicative of complex feedback mechanisms that may allow the cells to maintain $\mathrm{H}_{2} \mathrm{O}_{2}$ homeostasis. Since ROS are also involved in biotic stress response, studies are required to determine the role of $\mathrm{Ca}^{+2}$ $\mathrm{CaM}$ in regulating cross-talk between biotic- and abiotic stress pathways that enable the cells to maintain appropriate levels of ROS. Regulation of TFs by $\mathrm{Ca}^{+2}-\mathrm{CaM}$ appears to be a crucial factor in stress adaptation response of plants. CaM-regulated TFs are involved in both activation and suppression of stress responses. For instance, CAMTA3 acts as a suppressor of plant immunity, whereas GTL1 functions as a negative regulator of drought tolerance (Table 1). Furthermore, a given TF can also affect two processes differently. For example, CAMTA3 acts as a negative regulator of immune response as well as a positive regulator of the cold stress response (Table 1). It appears that the stress-specific functions of a TF are dependent upon the effector proteins that bind to the promoter regions of these genes. Identification of upstream DNA elements and regulatory proteins that bind to these regions will provide further insights into the molecular mechanisms which determine multiple functionality of $\mathrm{Ca}^{2+}$-CaM-regulated TFs. Studies are also needed to understand the significance of different domains that facilitate interaction of TFs, such as NAC, with $\mathrm{CaM}$ in $\mathrm{Ca}^{2+}$. dependent and $\mathrm{Ca}^{2+}$-independent manner. This will provide insights into the mechanisms that regulate the interaction of $\mathrm{CaM}$ with these proteins, and may also allow engineering of specific domains for improving stress tolerance of crop plants. As of now, very few stress-regulated CaM-binding TFs have been identified but a growing body of data suggests that many more such proteins could exist (Table 1). Therefore, there is a need to carry out systematic analysis for identification and characterization of CaM-regulated TFs. Cross-talk between different regulatory pathways also needs to be investigated for developing a comprehensive view of stress response in plants.

\section{References}

Akama, K., Akihiro, T., Kitagawa, M., and Takaiwa, F. (2001). Rice (Oryza sativa) contains a novel isoform of glutamate decarboxylase that lacks an authentic calmodulin-binding domain at the C-terminus. Biochim. Biophys. Acta 1522, 143-150. doi: 10.1016/S0167-4781(01)00324-4

Akama, K., and Takaiwa, F. (2007). C-terminal extension of rice glutamate decarboxylase (OsGAD2) functions as an autoinhibitory domain and overexpression of a truncated mutant results in the accumulation of extremely high levels of GABA in plant cells. J. Exp. Bot. 58, 2699-2707. doi: $10.1093 / \mathrm{jxb} / \mathrm{erm} 120$

Ali, R., Ma, W., Lemtiri-Chlieh, F., Tsaltas, D., Leng, Q., von Bodman, S., et al. (2007). Death don't have no mercy and neither does calcium: Arabidopsis CYCLIC NUCLEOTIDE GATED CHANNEL2 and innate immunity. Plant Cell 19, 1081-1095. doi: 10.1105/tpc.106.045096

Al-Quraan, N. A., Locy, R. D., and Singh, N. K. (2010). Expression of calmodulin genes in wild type and calmodulin mutants of Arabidopsis thaliana under
Regulation of several processes such as maintenance of $\mathrm{Ca}^{2+}$ and $\mathrm{H}_{2} \mathrm{O}_{2}$ homeostasis, and heat shock response by CaM appears to be mediated through complex feedback mechanisms involving interaction of several different pathways. It is evident that $\mathrm{CaM}$ is acting as a hub for integration of different signal transduction pathways that enable cells to respond to different stimuli and maintain homeostasis. System biology approach would, therefore, be helpful in developing a deeper understanding of these mechanisms. Another aspect that needs to be explored further is to understand the crosstalk between regulation of different stress-modulated CaMBPs and phytohormones. With advances in protein microarray, transcriptome, and genome sequencing technologies, the number of stress-regulated CaMBPs that are identified in economically important crops is expected to increase further. Analysis of these proteins by using functional genomics approaches will, therefore, be an important factor in unraveling novel candidate genes for improving stress tolerance of crops by biotechnological interventions.

\section{Acknowledgments}

We gratefully acknowledge the financial assistance provided by the Department of Biotechnology, Government of India, New Delhi. ASV and SS are thankful to Department of Science \& Technology, Govt. of India and Department of Biotechnology, Government of India, respectively, for the fellowships. ASV is thankful to Dr. Narpinder Singh, Department of Food Science \& Technology, Guru Nanak Dev University for providing the laboratory facilities. We express our gratitude to Dr. Sanjay Kapoor, Department of Plant Molecular Biology, University of Delhi South Campus, New Delhi, India for critical reading of the manuscript.

\section{Supplementary Material}

The Supplementary Material for this article can be found online at: http://journal.frontiersin.org/article/10.3389/fpls.2015. 00809

heat stress. Plant Physiol. Biochem. 48, 697-702. doi: 10.1016/j.plaphy.2010. 04.011

Alvarez Viveros, M. F., Inostroza-Blancheteau, C., Timmermann, T., González, M., and Arce-Johnson, P. (2013). Overexpression of GlyI and GlyII genes in transgenic tomato (Solanum lycopersicum Mill.) plants confers salt tolerance by decreasing oxidative stress. Mol. Biol. Rep. 40, 3281-3290. doi: 10.1007/s11033012-2403-4

Angilletta, M. J. (2009). Thermal Adaptation: A Theoretical and Empirical Synthesis. Oxford: Oxford University Press.

Arazi, T., Baum, G., Snedden, W. A., Shelp, B. J., and Fromm, H. (1995). Molecular and biochemical analysis of calmodulin interactions with the calmodulinbinding domain of plant glutamate decarboxylase. Plant Physiol. 108, 551-561. doi: $10.1104 /$ pp.108.2.551

Arazi, T., Sunkar, R., Kaplan, B., and Fromm, H. (1999). A tobacco plasma membrane calmodulin-binding transporter confers $\mathrm{Ni}^{2+}$ tolerance and $\mathrm{Pb}^{2+}$ hypersensitivity in transgenic plants. Plant J. 20, 171-182. doi: 10.1046/j.1365313x.1999.00588.x 
Axelson, K. B., and Palmgren, M. G. (1998). Evolution of substrate specificities in the P-type ATPase superfamily. J. Mol. Evol. 46, 84-101. doi: 10.1007/PL00006286

Babu, Y. S., Bugg, C. E., and Cook, W. J. (1988). Structure of calmodulin refined at 2.2 Å resolution. J. Mol. Biol. 204, 191-204. doi: 10.1016/0022-2836(88)90608-0

Banerjee, J., Magnani, R., Nair, M., Dirk, L. M., DeBolt, S., Maiti, I. B., et al. (2013). Calmodulin-mediated signal transduction pathways in Arabidopsis are finetuned by methylation. Plant Cell 25, 4493-4511. doi: 10.1105/tpc.113.119115

Baniwal, S. K., Bharti, K., Chan, K. Y., Fauth, M., Ganguli, A., Kotak, S., et al. (2004). Heat stress response in plants: a complex game with chaperones and more than twenty heat stress transcription factors. J. Biosci. 29, 471-487. doi: $10.1007 / \mathrm{BF} 02712120$

Baum, G., Chen, Y., Arazi, T., Takatsuji, H., and Fromm, H. (1993). A plant glutamate decarboxylase containing a calmodulin binding domain. Cloning, sequence, and functional analysis. J. Biol. Chem. 268, 19610-19617.

Baum, G., Lev-Yadun, S., Fridmann, Y., Arazi, T., Katsnelson, H., Zik, M., et al. (1996). Calmodulin binding to glutamate decarboxylase is required for regulation of glutamate and GABA metabolism and normal development in plants. EMBO J. 15, 2988-2996.

Bender, K. W., and Snedden, W. A. (2013). Calmodulin-related proteins step out from the shadow of their namesake. Plant Physiol. 163, 486-495. doi: 10.1104/pp.113.221069

Benn, G., Wang, C. Q., Hicks, D. R., Stein, J., Guthrie, C., and Dehesh, K. (2014). A key general stress response motif is regulated non-uniformly by CAMTA transcription factors. Plant J. 80, 82-92. doi: 10.1111/tpj.12620

Bjornson, M., Benn, G., Song, X., Comai, L., Franz, A. K., Dandekar, A. M., et al. (2014). Distinct roles for MAPK signaling and CAMTA3 in regulating the peak time and amplitude of the plant general stress response. Plant Physiol. 166, 988-996. doi: 10.1104/pp.114.245944

Bonza, M. C., Morandini, P., Luoni, L., Geisler, M., Palmgren, M. G., and De Michelis, M. I. (2000). At-ACA8 encodes plasma membrane-localized calcium ATPase of Arabidopsis with a calmodulin-binding domain at the $\mathrm{N}$ terminus. Plant Physiol. 123, 1495-1506. doi: 10.1104/pp.123.4.1495

Boonburapong, B., and Buaboocha, T. (2007). Genome-wide identification and analysis of the rice calmodulin and related potential calcium sensor proteins. BMC Plant Biol. 7:4. doi: 10.1186/1471-2229-7-4

Botella, J. R., and Arteca, R. N. (1994). Differential expression of two calmodulin genes in response to physical and chemical stimuli. Plant Mol. Biol. 24, 757-766. doi: 10.1007/BF00029857

Bouché, N., Fait, A., Zik, M., and Fromm, H. (2004). The root-specific glutamate decarboxylase (GAD1) is essential for sustaining GABA levels in Arabidopsis. Plant Mol. Biol. 55, 315-325. doi: 10.1007/s11103-004-0650-z

Bouché, N., Scharlat, A., Snedden, W., Bouchez, D., and Fromm, H. (2002). A novel family of calmodulin-binding transcription activators in multicellular organisms. J. Biol. Chem. 277, 21851-21886. doi: 10.1074/jbc.M2002 68200

Bouché, N., Yellin, A., Snedden, W. A., and Fromm, H. (2005). Plant-specific calmodulin-binding proteins. Annu. Rev. Plant Biol. 56, 435-466. doi: 10.1146/annurev.arplant.56.032604.144224

Bush, D. S. (1995). Calcium regulation in plant cells and its role in signaling. Annu. Rev. Plant Physiol. Plant Mol. Biol. 46, 95-122. doi: 10.1146/annurev.pp.46.060195.000523

Carrión, A. M., Link, W. A., Ledo, F., Mellstrom, B., and Naranjo, J. R. (1999). DREAM is a $\mathrm{Ca}^{2+}$-regulated transcriptional repressor. Nature 398, 80-84. doi: $10.1038 / 18044$

Chaerle, L., Saibo, N., and Van Der Straeten, D. (2005). Tuning the pores: towards engineering plants for improved water use efficiency. Trends Biotechnol. 23, 308-315. doi: 10.1016/j.tibtech.2005.04.005

Charpenteau, M., Jaworski, K., Ramirez, B. C., Tretyn, A., Ranjeva, R., and Ranty, B. T. (2004). A receptor-like kinase from Arabidopsis thaliana is a calmodulinbinding protein. Biochem. J. 379, 841-848. doi: 10.1042/bj20031045

Che, P., Bussell, J. D., Zhou, W., Estavillo, G. M., Pogson, B. J., and Smith, S. M. (2010). Signaling from the endoplasmic reticulum activates brassinosteroid signaling and promotes acclimation to stress in Arabidopsis. Sci. Signal. 3:ra69. doi: 10.1126/scisignal.2001140

Chen, Y. R., and Roux, S. J. (1986). Characterization of nucleoside triphosphatase activity in isolated pea nuclei and its photo reversible regulation by light. Plant Physiol. 81, 609-613. doi: 10.1104/pp.81.2.609
Chinpongpanich, A., Limruengroj, K., Phean-o-pas, S., Limpaseni, T., and Buaboocha, T. (2012). Expression analysis of calmodulin and calmodulin-like genes from rice, Oryza sativa L. BMC Res. Notes 5:625. doi: 10.1186/1756-05005-625

Choi, M. S., Kim, M. C., Yoo, J. H., Moon, B. C., Koo, S. C., Park, B. O., et al. (2005). Isolation of a calmodulin-binding transcription factor from rice (Oryza sativa L.). J. Biol. Chem. 280, 40820-40831. doi: 10.1074/jbc.M504616200

Chung, W. S., Lee, S. H., Kim, J. C., Heo, W. D., Kim, M. C., Park, C. Y., et al. (2000). Identification of a calmodulin-regulated soybean $\mathrm{Ca}^{2+}$-ATPase (SCA1) that is located in the plasma membrane. Plant Cell 12, 1393-1407. doi: 10.1105/tpc.12.8.1393

Clapham, D. E. (2007). Calcium signaling. Cell 1319, 1047-1058. doi: 10.1016/j.cell.2007.11.028

Coleman, S. T., Fang, T. K., Rovinsky, S. A., Turano, F. J., and Moye-Rowley, W. S. (2001). Expression of a glutamate decarboxylase homologue is required for normal oxidative stress tolerance in Saccharomyces cerevisiae. J. Biol. Chem. 75, 244-250. doi: 10.1074/jbc.M007103200

Corcoran, E. E., and Means, A. R. (2001). Defining $\mathrm{Ca}^{2+} /$ calmodulin-dependent protein kinase cascades in transcriptional regulation. J. Biol. Chem. 276, 2975-2978. doi: 10.1074/jbc.R000027200

Corneliussen, B., Holm, M., Waltersson, Y., Onions, J., Hallberg, B., Thornell, A., et al. (1994). Calcium/calmodulin inhibition of basic-helix-loop-helix transcription factor domains. Nature 368, 760-764. doi: 10.1038/368760a0

Das, R., Pandey, A., and Pandey, G. K. (2014). "Role of calcium/calmodulin in plant stress response and signaling," in Approaches to Plant Stress and their Management, eds R. K. Gaur and Pradeep Sharma (New Delhi: Springer India), 53-84.

Dauwalder, M., Roux, S. J., and Hardison, L. (1986). Distribution of calmodulin in pea seedlings: immunocytochemical localization in plumules and root apices. Planta 168, 461-470. doi: 10.1007/BF00392265

Dehesh, K., Hung, H., Tepperman, J. M., and Quail, P. H. (1992). GT-2: a transcription factor with twin autonomous DNA-binding domains of closely related but different target sequence specificity. EMBO J. 11, 4131-4144.

Del Río, L. A. (2015). ROS and RNS in plant physiology: an overview. J. Exp. Bot. 66, 2827-2837. doi: $10.1093 / \mathrm{jxb} /$ erv099

Deng, Y., Humbert, S., Liu, J. X., Srivastava, R., Rothstein, S. J., and Howella, S. H. (2011). Heat induces the splicing by IRE1 of a mRNA encoding a transcription factor involved in the unfolded protein response in Arabidopsis. Proc. Natl. Acad. Sci. U.S.A. 108, 7247-7252. doi: 10.1073/pnas.1102117108

Deswal, R., and Sopory, S. K. (1999). B. juncea glyoxalase I is a calmodulin stimulated protein. Biochim. Biophys. Acta 1450, 460-467. doi: 10.1016/S01674889(99)00047-6

Doherty, C. J., Van Buskirk, H. A., Myers, S. J., and Thomashow, M. F. (2009). Roles for Arabidopsis CAMTA transcription factors in cold-regulated gene expression and freezing tolerance. Plant Cell 21, 972-984. doi: 10.1105/tpc.108.063958

Du, L., Ali, G. S., Simons, K. A., Hou, J., Yang, T., Reddy, A. S. N., et al. (2009). $\mathrm{Ca}^{2+} /$ calmodulin regulates salicylic-acid-mediated plant immunity. Nature 457, 1154-1158. doi: 10.1038/nature07612

Emamverdian, A., Ding, Y., Mokhberdoran, F., and Xie, Y. (2015). Heavy metal stress and some mechanisms of plant defense response. Scientific World J. 2015:756120. doi: 10.1155/2015/756120

Eulgem, T., Rushton, P. J., Robatzek, S., and Somssich, I. E. (2000). WRKY superfamily of plant transcription factors. Trends Plant Sci. 5, 199-206. doi: 10.1016/S1360-1385(00)01600-9

Finkler, A., Ashery-Padan, R., and Fromm, H. (2007). CAMTAs: calmodulinbinding transcription activators from plants to human. FEBS Lett. 581, 3893-3898. doi: 10.1016/j.febslet.2007.07.051

Fischer, R., Koller, M., Flura, M., Mathews, S., Strehler-Page, M. A., Krebs, J., et al. (1988). Multiple divergent mRNAs code for a single human calmodulin. J. Biol. Chem. 263, 17055-17062.

Gallego, P. P., Whotton, L., Picton, S., Grierson, D., and Gray, J. E. (1995). A role for glutamate decarboxylase during tomato ripening: the characterization of a cDNA encoding a putative glutamate decarboxylase with a calmodulin-binding site. Plant Mol. Biol. 27, 1143-1151. doi: 10.1007/BF00020887

Galon, Y., Aloni, R., Nachmias, D., Snir, O., Feldmesser, E., Scrase-Field, S., et al. (2010). Calmodulin-binding transcription activator 1 mediates auxin signaling and responds to stresses in Arabidopsis. Planta 232, 165-178. doi: $10.1007 / \mathrm{s} 00425-010-1153-6$ 
Gao, H., Brandizzi, F., Benning, C., and Larkin, R. M. (2008). A membranetethered transcription factor defines a branch of the heat stress response in Arabidopsis thaliana. Proc. Natl. Acad. Sci. U.S.A. 105, 16398-16403. doi: 10.1073/pnas.0808463105

Ghorbel, M., Zaidi, I., Robe, E., Ranty, B., Mazars, C., Galaud, J. P., et al. (2015). The activity of the wheat MAP kinase phosphatase 1 is regulated by manganese and by calmodulin. Biochimie 108, 13-19. doi: 10.1016/j.biochi.2014.10.021

Gong, M., van der Luit, A. H., Knight, M. R., and Trewavas, A. J. (1998). Heat-shock-induced changes in intracellular $\mathrm{Ca}^{2+}$ level in tobacco seedlings in relation to thermotolerance. Plant Physiol. 116, 429-437. doi: 10.1104/pp.116.1.429

Gregori, L., Marriott, D., West, C. M., and Chau, V. (1985). Specific recognition of calmodulin from Dictyostelium discoideum by the ATP, ubiquitin-dependent degradative pathway. J. Biol. Chem. 260, 5232-5235.

Guo, F. Q., Okamoto, M., and Crawford, N. M. (2003). Identification of a plant nitric oxide synthase gene involved in hormonal signaling. Science 302, 100-103. doi: 10.1126/science. 1086770

Gurr, S. J., and Rushton, P. J. (2005). Engineering plants with increased disease resistance: what are we going to express? Trends Biotechnol. 23, 275-282. doi: 10.1016/j.tibtech.2005.04.007

Hampe, C. S., Lundgren, P., Daniels, T. L., Hammerle, L. P., Marcovina, S. M., and Lernmark, A. (2001). A novel monoclonal antibody specific for the Nterminal end of GAD65. J. Neuroimmunol. 113, 63-71. doi: 10.1016/S01655728(00)00423-9

Hardie, D. G. (1999). Plant protein serine/threonine kinases: classification and functions. Annu. Rev. Plant Physiol. Plant Mol. Biol. 50, 97-131. doi: 10.1146/annurev.arplant.50.1.97

Harding, S. A., Oh, S. H., and Roberts, D. M. (1997). Transgenic tobacco expressing a foreign calmodulin gene shows an enhanced production of active oxygen species. EMBO J. 16, 1137-1144. doi: 10.1093/emboj/16.6.1137

Harper, J. F., Hong, B., Hwang, I., Guo, H. Q., Stoddard, R., Hwang, J. F., et al. (1998). A novel calmodulin-regulated $\mathrm{Ca}^{2+}$-ATPase (ACA2) from Arabidopsis with an N-terminal auto inhibitory domain. J. Biol. Chem. 273, 1099-1106. doi: 10.1074/jbc.273.2.1099

Høj, A., and Jakobsen, B. K. (1994). A short element required for turning off heat shock transcription factor: evidence that phosphorylation enhances deactivation. EMBO J. 13, 2617-2624.

Hong, B., Ichida, A., Wang, Y., Gens, J. S., Pickard, B. G., and Harper, J. F. (1999). Identification of a calmodulin regulated $\mathrm{Ca}^{2+}$-ATPase in the endoplasmic reticulum. Plant Physiol. 119, 1165-1175. doi: 10.1104/pp.119.4.1165

Hu, H., Dai, M., Yao, J., Xiao, B., Li, X., Zhang, Q., et al. (2006). Overexpressing a NAM, ATAF, and CUC (NAC) transcription factor enhances drought resistance and salt tolerance in rice. Proc. Natl. Acad. Sci. U.S.A. 103, 12987-12992. doi: 10.1073/pnas.0604882103

Hua, W., Liang, S., and Lu, Y. T. (2003). A tobacco (Nicotiana tabaccum) calmodulin-binding protein kinase, $\mathrm{NtCBK} 2$, is regulated differentially by calmodulin isoforms. Biochem. J. 376, 291-302. doi: 10.1042/bj20030736

Hua, W., Li, R. J., Wang, L., and Lu, Y. T. (2004). A tobacco calmodulin-binding protein kinase (NtCBK2) induced by high-salt/GA treatment and its expression during floral development and embryogenesis. Plant Sci. 166, 1253-1259. doi: 10.1016/j.plantsci.2004.01.003

Huang, L., Berkelman, T., Franklin, A. E., and Hoffman, N. E. (1993). Characterization of a gene encoding $\mathrm{Ca}^{2+}$-ATPase-like protein in the plastid envelope. Proc. Natl. Acad. Sci. U.S.A. 90, 10066-10070. doi: 10.1073/pnas.90.21.10066

Jarrett, H. W., Brown, C. J., Black, C. C., and Cormier, M. J. (1982). Evidence that calmodulin is in the chloroplast of peas and serves a regulatory role in photosynthesis. J. Biol. Chem. 257, 13795-13804.

Johanson, B. S., Singh, N. K., Cherry, J. H., and Locy, R. D. (1997). Purification and characterization of glutamate decarboxylase from cowpea. Phytochemistry 46, 39-44. doi: 10.1016/S0031-9422(97)00236-7

Jung, K. Y., Kyung, C. E., In, L. S., Lim, C. O., and Ju, C. Y. (2010). Differential expression of rice calmodulin promoters in response to stimuli and developmental tissue in transgenic tobacco plants. BMB Rep. 43, 9-16. doi: 10.5483/BMBRep.2010.43.1.009

Katou, S., Kuroda, K., Seo, S., Yanagawa, Y., Tsuge, T., Yamazaki, M., et al. (2007). A calmodulin-binding mitogen-activated protein kinase phosphatase is induced by wounding and regulates the activities of stress related mitogen-activated protein kinases in rice. Plant Cell Physiol. 48, 332-344. doi: $10.1093 / \mathrm{pcp} / \mathrm{pcm} 007$

Kaur, C., Ghosh, A., Pareek, A., Sopory, S. K., and Singla-Pareek, S. L. (2014a). Glyoxalases and stress tolerance in plants. Biochem. Soc. Trans. 42, 485-490. doi: 10.1042/BST20130242

Kaur, C., Singla-Pareek, S. L., and Sopory, S. K. (2014b). Glyoxalase and methylglyoxal as biomarkers for plant stress tolerance. Crit. Rev. Plant Sci. 33, 429-456. doi: 10.1080/07352689.2014.904147

Kaur, C., Vishnoi, A., Ariyadasa, T. U., Bhattacharya, A., Singla-Pareek, S. L., and Sopory, S. K. (2013). Episodes of horizontal gene-transfer and gene-fusion led to co-existence of different metal-ion specific glyoxalase I. Sci. Rep. 3:3076. doi: $10.1038 /$ srep03076

Keller, T., Damude, H. G., Werner, D., Doerner, P., Dixon, R. A., and Lamb, C. (1998). A plant homolog of the neutrophil NADPH oxidase gp91 ${ }^{\text {phox }}$ subunit gene encodes a plasma membrane protein with $\mathrm{Ca}^{2+}$ binding motifs. Plant Cell 10, 255-266. doi: 10.1105/tpc.10.2.255

Kim, H. S., Park, B. O., Yoo, J. H., Jung, M. S., Lee, S. M., Han, H. J., et al. (2007). Identification of a calmodulin-binding NAC protein as a transcriptional repressor in Arabidopsis. J. Biol. Chem. 282, 36292-36302. doi: 10.1074/jbc.M705217200

Klee, C. B., and Vanaman, T. C. (1982). Calmodulin. Adv. Protein Chem. 35, 213-321. doi: 10.1016/S0065-3233(08)60470-2

Knight, H., Trewavas, A. J., and Knight, M. R. (1996). Cold calcium signaling in Arabidopsis involves two cellular pools and a change in calcium signature after acclimation. Plant Cell 8, 489-503. doi: 10.1105/tpc.8.3.489

Köhler, C., Merkle, T., and Neuhaus, G. (1999). Characterization of a novel gene family of putative cyclic nucleotide- and calmodulin-regulated ion channels in Arabidopsis thaliana. Plant J. 18, 97-104. doi: 10.1046/j.1365313X.1999.00422.x

Kranz, H. D., Denekamp, M., Greco, R., Jin, H., Leyva, A., Meissner, R. C., et al. (1998). Towards functional characterisation of the members of the R2R3-MYB gene family from Arabidopsis thaliana. Plant J. 16, 263-276. doi: 10.1046/j.1365-313x.1998.00278.x

Kutuzov, M. A., Bennett, N., and Andreeva, A. V. (2001). Interaction of plant protein Ser/Thr phosphatase PP7 with calmodulin. Biochem. Biophys. Res. Commun. 289, 634-640. doi: 10.1006/bbrc.2001.6020

Lecourieux, D., Ranjeva, R., and Pugin, A. (2006). Calcium in plant defence-signalling pathways. New Phytol. 171, 249-269. doi: 10.1111/j.1469-8137.2006.01777.x

Lee, J. H., Kim, Y. J., Jeone, D. Y., Sathiyaraj, G., Pulla, R. K., Shim, J. S., et al. (2010). Isolation and characterization of a glutamate decarboxylase (GAD) gene and their differential expression in response to abiotic stresses from Panax ginseng C. A. Meyer. Mol. Biol. Rep. 37, 3455-3463. doi: 10.1007/s11033-009-9937-0

Lee, K., Song, E. H., Kim, H. S., Yoo, J. H., Han, H. J., Jung, M. S., et al. (2008). Regulation of MAPK phosphatase 1 (AtMKP1) by calmodulin in Arabidopsis. J. Biol. Chem. 283, 23581-23588. doi: 10.1074/jbc.M801549200

Li, B., Liu, H. T., Sun, D. Y., and Zhou, R. G. (2004). Ca ${ }^{(2+)}$ and calmodulin modulate DNA-binding activity of maize heat shock transcription factor in vitro. Plant Cell Physiol. 45, 627-634. doi: 10.1093/pcp/pch074

Lin, F., Xu, J., Shi, J., Li, H., and Li, B. (2010). Molecular cloning and characterization of a novel glyoxalase I gene TaGLY I in wheat (Triticum aestivum L.). Mol. Biol. Rep. 37, 729-735. doi: 10.1007/s11033-009-9578-3

Li, S., Zhou, X., Chen, L., Huang, W., and Yu, D. (2010). Functional characterization of Arabidopsis thaliana WRKY39 in heat stress. Mol. Cells 29, 475-483. doi: 10.1007/s10059-010-0059-2

Liu, H. T., Gao, F., Li, G. L., Han, J. L., Liu, D. L., Sun, D. Y., et al. (2008). The calmodulin-binding protein kinase 3 is part of heat-shock signal transduction in Arabidopsis thaliana. Plant J. 55, 760-773. doi: 10.1111/j.1365313X.2008.03544.X

Liu, H. T., Li, B., Shang, Z. L., Li, X. Z., Mu, R. L., Sun, D. Y., et al. (2003). Calmodulin is involved in heat shock signal transduction in wheat. Plant Physiol. 132, 1186-1195. doi: 10.1104/pp.102.018564

Liu, H. T., Li, G. L., Chang, H., Sun, D. Y., Zhou, R. G., and Li, B. (2007) Calmodulin-binding protein phosphatase PP7 is involved in thermotolerance in Arabidopsis. Plant Cell Environ. 30, 156-164. doi: 10.1111/j.13653040.2006.01613.x

Liu, H. T., Sun, D. Y., and Zhou, R. G. (2005). $\mathrm{Ca}^{2+}$ and AtCaM3 are involved in the expression of heat shock protein gene in Arabidopsis. 
Plant, Cell Environ. 28, 1276-1284. doi: 10.1111/j.1365-3040.2005. 01365.x

Liu, J., Whalley, H. J., and Knight, M. R. (2015). Combining modelling and experimental approaches to explain how calcium signatures are decoded by calmodulin-binding transcription activators (CAMTAs) to produce specific gene expression responses. New Phytol. 208, 174-187. doi: 10.1111/nph.13428

Liu, Z., Xia, M., and Poovaiah, B. W. (1998). Chimeric calcium/calmodulindependent protein kinase in tobacco: differential regulation by calmodulin isoforms. Plant Mol. Biol. 38, 889-897. doi: 10.1023/A:1006019001200

Luoni, L., Bonza, M. C., and De Michelis, M. I. (2006). Calmodulin/Ca ${ }^{2+}$ ATPase interaction at the Arabidopsis thaliana plasma membrane is dependent on calmodulin isoform showing isoform-specific $\mathrm{Ca}^{2+}$ dependencies. Physiol. Plant. 126, 175-186. doi: 10.1111/j.1399-3054.2006.00588.x

Ma, L., Liang, S. P., Jones, R. L., and Lu, Y. T. (2004). Characterization of a novel calcium/calmodulin-dependent protein kinase from tobacco. Plant Physiol. 135, 1280-1293. doi: 10.1104/pp.104.041970

Ma, L., Xu, X., Cui, S., and Sun, D. (1999). The presence of a heterotrimeric $\mathrm{G}$ protein and its role in signal transduction of extracellular calmodulin in pollen germination and tube growth. Plant Cell 11, 1351-1364. doi: 10.1105/tpc.11.7.1351

Magnani, R., Dirk, L. M., Trievel, R. C., and Houtz, R. L. (2010). Calmodulin methyltransferase is an evolutionarily conserved enzyme that trimethylates Lys-115 in calmodulin. Nat. Commun. 1:43. doi: 10.1038/ncomms1044

Malmström, S., Askerlund, P., and Palmgren, M. G. (1997). A calmodulinstimulated $\mathrm{Ca}^{2+}$-ATPase from plant vacuolar membranes with a putative regulatory domain at its N-terminus. FEBS Lett. 400, 324-328. doi: 10.1016/S0014-5793(96)01448-2

Mannervik, B., and Ridderström, M. (1993). Catalytic and molecular properties of glyoxalase I. Biochem. Soc. Trans. 21, 515-517. doi: 10.1042/bst0210515

Marcus, A. J., Broekman, M. J., Drosopoulos, J. H., Islam, N., Alyonycheva, T. N., Safier, L. B., et al. (1997). The endothelial cell ecto-ADPase responsible for inhibition of platelet function is CD39. J. Clin. Invest. 99, 1351-1360. doi: 10.1172/JCI119294

Maruyama, K., Sakuma, Y., Kasuga, M., Ito, Y., Seki, M., Goda, H., et al. (2004). Identification of cold-inducible downstream genes of the Arabidopsis DREB1A/CBF3 transcriptional factor using two microarray systems. Plant J. 38, 982-993. doi: 10.1111/j.1365-313X.2004.02100.x

McClung, C. R. (1997). Regulation of catalases in Arabidopsis. Free Radic. Biol. Med. 23, 489-496. doi: 10.1016/S0891-5849(97)00109-3

McCormack, E., Tsai, Y. C., and Braam, J. (2005). Handling calcium signaling: Arabidopsis CaMs and CMLs. Trends Plant Sci. 10, 383-389. doi: 10.1016/j.tplants.2005.07.001

Meiri, D., and Breiman, A. (2009). Arabidopsis ROF1 (FKBP62) modulates thermotolerance by interacting with HSP90.1 and affecting the accumulation of HsfA2-regulated sHSPs. Plant J. 59, 387-399. doi: 10.1111/j.1365313X.2009.03878.x

Mishkind, M., Vermeer, J. E., Darwish, E., and Munnik, T. (2009). Heat stress activates phospholipase D and triggers PIP2 accumulation at the plasma membrane and nucleus. Plant J. 60, 10-21. doi: 10.1111/j.1365313X.2009.03933.x

Mittler, R. (2002). Oxidative stress, antioxidants and stress tolerance. Trends Plant Sci. 7, 405-410. doi: 10.1016/S1360-1385(02)02312-9

Mittler, R., Finka, A., and Goloubinoff, P. (2012). How do plants feel the heat? Trends Biochem. Sci. 37, 118-125. doi: 10.1016/j.tibs.2011.11.007

Mody, I., Dekoninck, Y., Otis, T. S., and Soltesz, I. (1994). Bringing the cleft at GABA synapses in the brain. Trends Neurosci. 17, 517-525. doi: 10.1016/01662236(94)90155-4

Mosser, D. D., Kotzbauer, P. T., Sarge, K. D., and Morimoto, R. I. (1990). In vitro activation of heat shock transcription factor DNA-binding by calcium and biochemical conditions that affect protein conformation. Proc. Natl. Acad. Sci. U.S.A. 87, 3748-3752. doi: 10.1073/pnas.87.10.3748

Mustafiz, A., Singh, A. K., Pareek, A., Sopory, S. K., and Singla-Pareek, S. L. (2011). Genome-wide analysis of rice and Arabidopsis identifies two glyoxalase genes that are highly expressed in abiotic stresses. Funct. Integr. Genomics 11, 293-305. doi: 10.1007/s10142-010-0203-2

Nobel, P. S. (1999). Physicochemical \& Environmental Plant Physiology. San Diego, CA: Academic Press.

Nover, L., Bharti, K., Döring, P., Mishra, S. K., Ganguli, A., and Scharf, K. D. (2001). Arabidopsis and the heat stress transcription factor world: how many heat stress transcription factors do we need? Cell Stress Chaperones 6, 177-189. doi: 10.1379/1466-1268(2001)006<0177:AATHST > 2.0.CO;2

Nuruzzaman, M., Manimekalai, R., Sharoni, A. M., Satoh, K., Kondoh, H., Ooka, H., et al. (2010). Genome-wide analysis of NAC transcription factor family in rice. Gene 465, 30-44. doi: 10.1016/j.gene.2010. 06.008

O'Neil, K. T., and DeGrado, W. F. (1990). How calmodulin binds its targets: sequence independent recognition of amphiphilic alpha-helices. Trends Biochem. Sci. 15, 59-64.

Oh, S. H., Choi, W. G., Lee, I. T., and Yun, S. J. (2005). Cloning and characterization of a rice cDNA encoding glutamate decarboxylase. J. Biochem. Mol. Biol. 38, 595-601. doi: 10.5483/BMBRep.2005.38.5.595

Ovečka, M., and Takáč, T. (2014). Managing heavy metal toxicity stress in plants: biological and biotechnological tools. Biotechnol. Adv. 32, 73-86. doi: 10.1016/j.biotechadv.2013.11.011

Owens-Grillo, J. K., Czar, M. J., Hutchison, K. A., Hoffmann, K., Perdew, G. H., and Pratt, W. B. (1996). A model of protein targeting mediated by immunophilins and other proteins that bind to hsp90 via tetratricopeptide repeat domains. J. Biol. Chem. 271, 13468-13475. doi: 10.1074/jbc.271.23.13468

Pandey, N., Ranjan, A., Pant, P., Tripathi, R. K., Ateek, F., Pandey, H. P., et al. (2013). CAMTA 1 regulates drought responses in Arabidopsis thaliana. BMC Genomics 14:216. doi: 10.1186/1471-2164-14-216

Pandey, S., and Sopory, S. K. (1998). Biochemical evidence for a calmodulinstimulated calcium-dependent protein kinase in maize. Eur. J. Biochem. 255, 718-726. doi: 10.1046/j.1432-1327.1998.2550718.x

Pandey, S., and Sopory, S. K. (2001). Zea mays CCaMK: autophosphorylationdependent substrate phosphorylation and down-regulation by red light. J. Exp. Bot. 52, 691-700. doi: 10.1093/jexbot/52.357.691

Park, C. Y., Lee, J. H., Yoo, J. H., Moon, B. C., Choi, M. S., Kang, Y. H., et al. (2005). WRKY group IId transcription factors interact with calmodulin. FEBS Lett. 579, 1545-1550. doi: 10.1016/j.febslet.2005.01.057

Park, H. C., Kim, M. L., Kang, Y. H., Jeong, J. C., Cheong, M. S., Choi, W., et al. (2009). Functional analysis of the stress-inducible soybean calmodulin isoform4 (GmCaM-4) promoter in transgenic tobacco plants. Mol. Cells 27, 475-480. doi: 10.1007/s10059-009-0063-6

Park, H. C., Kim, M. L., Kang, Y. H., Jeon, J. M., Yoo, J. H., Kim, M. C., et al. (2004). Pathogen- and NaCl-induced expression of the SCaM-4 promoter is mediated in part by a GT-1 box that interacts with a GT-1-like transcription factor. Plant Physiol. 135, 2150-2161. doi: 10.1104/pp.104.041442

Pedley, K. F., and Martin, G. B. (2005). Role of mitogen-activated protein kinases in plant immunity. Curr. Opin. Plant Biol. 8, 541-547. doi: 10.1016/j.pbi.2005.07.006

Pei, Z. M., Murata, Y., Benning, G., Thomine, S., Klüsener, B., Allen, G. J., et al. (2000). Calcium channels activated by hydrogen peroxide mediate abscisic acid signalling in guard cells. Nature 406, 731-734. doi: 10.1038/35021067

Peng, S., Huang, J., Sheehy, J. E., Laza, R. C., Visperas, R. M., Zhong, X., et al. (2004). Rice yields decline with higher night temperature from global warming. Proc. Natl. Acad. Sci. U.S.A. 101, 9971-9975. doi: 10.1073/pnas.0403720101

Perruc, E., Charpenteau, M., Ramirez, B. C., Jauneau, A., Galaud, J. P., Ranjeva, R., et al. (2004). A novel calmodulin-binding protein functions as a negative regulator of osmotic stress tolerance in Arabidopsis thaliana seedlings. Plant J. 38, 410-420. doi: 10.1111/j.1365-313X.2004.02062.x

Popescu, S. C., Popescu, G. V., Bachan, S., Zhang, Z., Seay, M., Gerstein, M., et al. (2007). Differential binding of calmodulin related proteins to their targets revealed through high-density Arabidopsis protein microarrays. Proc. Natl. Acad. Sci. U.S.A 104, 4730-4735. doi: 10.1073/pnas.0611615104

Pratt, W. B., and Toft, D. O. (1997). Steroid receptor interactions with heat shock protein and immunophilin chaperones. Endocr. Rev. 18, 306-360. doi: 10.1210/er.18.3.306

Price, A. H., Taylor, A., Ripley, S. J., Griffiths, A., Trewavas, A. J., and Knight, M. R. (1994). Oxidative signals in tobacco increase cytosolic calcium. Plant Cell 6, 1301-1310. doi: 10.1105/tpc.6.9.1301

Puranik, S., Sahu, P. P., Mandal, S. N., Suresh, B. V., Parida, S. K., and Prasad, M. (2013). Comprehensive genome-wide survey, genomic constitution and expression profiling of the NAC transcription factor family in Foxtail millet (Setaria italica L.). PLoS ONE 8:e64594. doi: 10.1371/journal.pone.0064594

Queitsch, C., Hong, S. W., Vierling, E., and Lindquist, S. (2000). Heat shock protein 101 plays a crucial role in thermotolerance in Arabidopsis. Plant Cell 12, 479-492. doi: 10.1105/tpc.12.4.479 
Reddy, A. S., Ali, G. S., Celesnik, H., and Day, I. S. (2011). Coping with stresses: roles of calcium- and calcium/calmodulin-regulated gene expression. Plant Cell 23, 2010-2032. doi: 10.1105/tpc.111.084988

Reddy, A. S. N. (2001). Calcium: silver bullet in signaling. Plant Sci. 160, 381-404. doi: 10.1016/S0168-9452(00)00386-1

Reddy, V. S., Ali, G. S., and Reddy, A. S. N. (2002). Genes encoding calmodulinbinding proteins in the Arabidopsis genome. J. Biol. Chem. 277, 9840-9852. doi: 10.1074/jbc.M111626200

Reindl, A., Schöffl, F., Schell, J., Koncz, C., and Bakó, L. (1997). Phosphorylation by a cyclin-dependent kinase modulates DNA binding of the Arabidopsis heatshock transcription factor HSF1 in vitro. Plant Physiol. 115, 93-100. doi: 10.1104/pp.115.1.93

Rhoads, A. R., and Friedberg, F. (1997). Sequence motifs for calmodulin recognition. FASEB J. 11, 331-340.

Richard, J. P. (1993). Mechanism for the formation of methylglyoxal from triosephosphates. Biochem. Soc. Trans. 21, 549-553. doi: 10.1042/bst0210549

Riechmann, J. L., Heard, J., Martin, G., Reuber, L., Jiang, C., Keddie, J., et al. (2000). Arabidopsis transcription factors: genome-wide comparative analysis among eukaryotes. Science 290, 2105-2110. doi: 10.1126/science.290.5499.2105

Roberts, D. M., Burgess, W. H., and Watterson, D. M. (1984). Comparison of the NAD kinase and myosin light chain kinase activator properties of vertebrate, higher plant, and algal calmodulins. Plant Physiol. 75, 796-798. doi: 10.1104/pp.75.3.796

Roberts, D. M., Rowe, P. M., Siegel, F. L., Lukas, T. J., and Watterson, D. M. (1986). Trimethyllysine and protein function. Effect of methylation and mutagenesis of lysine 115 of calmodulin on NAD kinase activation. J. Biol. Chem. 261, 1491-1494.

Roberts, D. M., Zielinski, R. E., Schleicher, M., and Watterson, D. M. (1983). Analysis of sub-organellar fractions from spinach and pea chloroplasts for calmodulin-binding proteins. J. Cell Biol. 97, 1644-1647. doi: 10.1083/jcb.97.5.1644

Rodriguez-Concepcion, M., Yalovsky, S., Zik, M., Fromm, H., and Gruissem, W. (1999). The prenylation status of a novel plant calmodulin directs plasma membrane or nuclear localization of the protein. EMBO J. 18, 1996-2007. doi: 10.1093/emboj/18.7.1996

Rushton, P. J., Somssich, I. E., Ringler, P., and Shen, Q. J. (2010). WRKY transcription factors. Trends Plant Sci. 15, 247-258. doi: 10.1016/j.tplants.2010.02.006

Sanders, D., Brownlee, C., and Harper, J. F. (1999). Communicating with calcium. Plant Cell 11, 691-706. doi: 10.1105/tpc.11.4.691

Sangwan, V., Orvar, B. L., Beyerly, J., Hirt, H., and Dhindsa, R. S. (2002). Opposite changes in membrane fluidity mimic cold and heat stress activation of distinct plant MAP kinase pathway. Plant J. 31, 629-638. doi: 10.1046/j.1365313X.2002.01384.x

Sathyanarayanan, P. V., Siems, W. F., Jones, J. P., and Poovaiah, B. W. (2001). Calcium-stimulated autophosphorylation site of plant chimeric calcium/calmodulin-dependent protein kinase. J. Biol. Chem. 276, 32940-32947. doi: 10.1074/jbc.M009648200

Scandalios, J. G., Guan, L. M., and Polidoros, A. (1997). "Catalases in plants: gene structure, properties, regulation, and expression," in Oxidative Stress and the Molecular Biology of Antioxidant Defenses, ed. J. G. Scandalios (New York, NY: Cold Spring Harbor Laboratory Press), 343-406.

Schreiber, S. L. (1991). Chemistry and biology of the immunophilins and their immunosuppressive ligands. Science 251, 283-287. doi: 10.1126/science.1702904

Shin, R., Burch, A. Y., Huppert, K. A., Tiwari, S. B., Murphy, A. S., Guilfoyle, T. J., et al. (2007). The Arabidopsis transcription factor MYB77 modulates auxin signal transduction. Plant Cell 19, 2440-2453. doi: 10.1105/tpc.107.050963

Shpak, E. D., McAbee, J. M., Pillitteri, L. J., and Torii, K. U. (2005). Stomatal patterning and differentiation by synergistic interactions of receptor kinases. Science 309, 290-293. doi: 10.1126/science.1109710

Singla-Pareek, S. L., Reddy, M. K., and Sopory, S. K. (2003). Genetic engineering of the glyoxalase pathway in tobacco leads to enhanced salinity tolerance. Proc. Natl. Acad. Sci. U.S.A. 100, 14672-14677. doi: 10.1073/pnas.20346 67100

Singla-Pareek, S. L., Yadav, S. K., Pareek, A., Reddy, M. K., and Sopory, S. K. (2006). Transgenic tobacco overexpressing glyoxalase pathway enzymes grow and set viable seeds in zinc-spiked soils. Plant Physiol. 140, 613-623. doi: 10.1104/pp.105.073734

Snedden, W. A., Arazi, T., Fromm, H., and Shelp, B. J. (1995). Calcium/calmodulin activation of soybean glutamate decarboxylase. Plant Physiol. 108, 543-549.

Snedden, W. A., and Fromm, H. (2001). Calmodulin as a versatile calcium signal transducer in plants. New Phytol. 151, 35-66. doi: 10.1046/j.14698137.2001.00154.x

Steinebrunner, I., Jeter, C., Song, C., and Roux, S. J. (2000). Molecular and biochemical comparison of two different apyrases from Arabidopsis thaliana. Plant Physiol. Biochem. 38, 913-922. doi: 10.1016/S0981-9428(00)01209-2

Stone, J. M., and Walker, J. C. (1995). Plant protein kinase families and signal transduction. Plant Physiol. 108, 451-457. doi: 10.1104/pp.108.2.451

Sun, X. T., Li, B., Zhou, G. M., Tang, W. Q., Bai, J., Sun, D. Y., et al. (2000). Binding of the maize cytosolic HSP70 to calmodulin, and identification of calmodulin-binding site in HSP70. Plant Cell Physiol. 41, 804-810. doi: $10.1093 / \mathrm{pcp} / 41.6 .804$

Sunkar, R., Kaplan, B., Bouché, N., Arazi, T., Dolev, D., Talke, I. N., et al. (2000). Expression of a truncated tobacco NtCBP4 channel in transgenic plants and disruption of the homologous Arabidopsis $\mathrm{CNGC1}$ gene confer $\mathrm{Pb}^{2+}$ tolerance. Plant J. 24, 533-542. doi: 10.1046/j.1365-313x.2000.00901.x

Thomas, C., Rajagopal, A., Windsor, B., Dudler, R., Lloyd, A., and Roux, S. J. (2000). A role for ectophosphatase in xenobiotic resistance. Plant Cell 12, 519-534. doi: 10.1105/tpc.12.4.519

The Arabidopsis Genome Initiative. (2000). Analysis of the genome sequence of the flowering plant Arabidopsis thaliana. Nature 408, 796-815. doi: $10.1038 / 35048692$

Todorov, L. D., Mihaylova-Todorova, S., Westfall, T. D., Sneddon, P., Kennedy, C., Bjur, R. A., et al. (1997). Neuronal release of soluble nucleotidases and their role in neurotransmitter inactivation. Nature 387, 76-79. doi: 10.1038/387 $076 \mathrm{a} 0$

Torii, K. U. (2000). Receptor kinase activation and signal transduction in plants: an emerging picture. Curr. Opin. Plant Biol. 3, 361-367. doi: 10.1016/S13695266(00)00097-2

Tran, L. S., Nakashima, K., Sakuma, Y., Simpson, S. D., and Fujita, Y. (2004). Isolation and functional analysis of Arabidopsis stress inducible NAC transcription factors that bind to a drought-responsive cis-element in the early responsive to dehydration stress 1 promoter. Plant Cell 16, 2481-2498. doi: $10.1105 /$ tpc.104.022699

Tripathi, P., Rabara, R. C., and Rushton, P. J. (2014). A systems biology perspective on the role of WRKY transcription factors in drought responses in plants. Planta 239, 255-266. doi: 10.1007/s00425-013-1985-y

Turano, F. J., and Fang, T. K. (1998). Characterization of two glutamate decarboxylase cDNA clones from Arabidopsis. Plant Physiol. 117, 1411-1421 doi: $10.1104 /$ pp.117.4.1411

Ueno, H. (2000). Enzymatic and structural aspects on glutamate decarboxylase. J. Mol. Catal. B 10, 67-79. doi: 10.1016/S1381-1177(00)00114-4

van Der Luit, A. H., Olivari, C., Haley, A., Knight, M. R., and Trewavas, A. J. (1999). Distinct calcium signaling pathways regulate calmodulin gene expression in tobacco. Plant Physiol. 121, 705-714. doi: 10.1104/pp.121.3.705

Virdi, A. S., Pareek, A., and Singh, P. (2011). Evidence for the possible involvement of calmodulin in regulation of steady state levels of Hsp90 family members (Hsp87 and Hsp85) in response to heat shock in sorghum. Plant Signal. Behav. 6, 393-399. doi: 10.4161/psb.6.3.13867

Virdi, A. S., Thakur, A., Dutt, S., Kumar, S., and Singh, P. (2009). A sorghum 85 kDa heat stress-modulated protein shows calmodulin-binding properties and crossreactivity to anti-Neurospora crassa Hsp 80 antibodies. FEBS Lett. 583, 767-770. doi: 10.1016/j.febslet.2009.01.025

von Groll, U., Berger, D., and Altmann, T. (2002). The subtilisin-like serine protease SDD1 mediates cell-to-cell signaling during Arabidopsis stomatal development. Plant Cell 14, 1527-1539. doi: 10.1105/tpc.001016

Wan, D., Li, R., Zou, B., Zhang, X., Cong, J., Wang, R., et al. (2012). Calmodulinbinding protein CBP60g is a positive regulator of both disease resistance and drought tolerance in Arabidopsis. Plant Cell Rep. 31, 1269-1281. doi: 10.1007/s00299-012-1247-7

Wang, C., Zhang, Q., and Shou, H. X. (2009a). Identification and expression analysis of OsHsfs in rice. J. Zhejiang. Univ. Sci. B 10, 291-300. doi: 10.1631/jzus.B0820190 
Wang, L., Guo, Y., Jia, L., Chu, H., Zhou, S., Chen, K., et al. (2014a). Hydrogen peroxide acts upstream of nitric oxide in the heat shock pathway in Arabidopsis seedlings. Plant Physiol. 164, 2184-2196. doi: 10.1104/pp.113.229369

Wang, L., Tsuda, K., Sato, M., Cohen, J. D., Katagiri, F., and Glazebrook, J. (2009b). Arabidopsis CaM binding protein CBP60g contributes to MAMP induced SA accumulation and is involved in disease resistance against Pseudomonas syringae. PLoS Pathog. 5:e1000301. doi: 10.1371/journal.ppat.1000301

Wang, W., Vinocur, B., Shoseyov, O., and Altman, A. (2004). Role of plant heatshock proteins and molecular chaperones in the abiotic stress response. Trends Plant Sci. 9, 244-252. doi: 10.1016/j.tplants.2004.03.006

Wang, X. H., Li, Q. T., Chen, H. W., Zhang, W. K., Ma, B., Chen, S. Y., et al. (2014b). Trihelix transcription factor GT-4 mediates salt tolerance via interaction with TEM2 in Arabidopsis. BMC Plant Biol. 14:339. doi: 10.1186/s12870-014-0339-7

Weng, H., Yoo, C. Y., Gosney, M. J., Hasegawa, P. M., and Mickelbart, M. V. (2012). Poplar GTL1 is a $\mathrm{Ca}^{2+} /$ calmodulin-binding transcription factor that functions in plant water use efficiency and drought tolerance. PLoS ONE 7:e32925. doi: 10.1371/journal.pone.0032925

Windsor, B., Roux, S. J., and Lloyd, A. (2003). Multi-herbicide tolerance conferred by AtPgp1 and apyrase overexpression in Arabidopsis thaliana. Nat. Biotechnol. 21, 428-433. doi: 10.1038/nbt809

Wu, C., Ma, C., Pan, Y., Gong, S., Zhao, C., Chen, S., et al. (2013). Sugar beet M14 glyoxalase I gene can enhance plant tolerance to abiotic stresses. J. Plant. Res. 126, 415-425. doi: 10.1007/s10265-012-0532-4

Wu, H. C., Luo, D. L., Vignols, F., and Jinn, T. L. (2012). Heat shockinduced biphasic $\mathrm{Ca}^{2+}$ signature and OsCaM1-1 nuclear localization mediate downstream signalling in acquisition of thermotolerance in rice (Oryza sativa L.). Plant Cell Environ. 35, 1543-1557. doi: 10.1111/j.1365-3040.2012. 02508.x

Xie, Q., Wang, Y., Liang, S., and Lu, Y. (2003). Characterization of a calmodulin binding protein kinase from Arabidopsis thaliana. Chi. Sci. Bul. 48, 57-62. doi: 10.1007/BF03183335

Xiong, L., Schumaker, K. S., and Zhu, J. K. (2002). Cell signaling during cold, drought, and salt stress. Plant Cell 14(Suppl.), S165-S183. doi: 10.1105/tpc.000596

Xu, X., Song, H., Zhou, Z., Shi, N., Ying, Q., and Wang, H. (2010). Functional characterization of AtHsp90.3 in Saccharomyces cerevisiae and Arabidopsis thaliana under heat stress. Biotechnol. Lett. 32, 979-987. doi: 10.1007/s10529010-0240-x

Xuan, Y., Zhou, S., Wang, L., Cheng, Y., and Zhao, L. (2010). Nitric oxide functions as a signal and acts upstream of AtCaM3 in thermotolerance in Arabidopsis seedlings. Plant Physiol. 153, 1895-1906. doi: 10.1104/pp.110. 160424

Yadav, S. K., Singla-Pareek, S. L., Reddy, M. K., and Sopory, S. K. (2005). Methylglyoxal detoxification by glyoxalase system: a survival strategy during environmental stresses. Physiol. Mol. Biol. Plants 11, 1-11.

Yamada, K., Fukao, Y., Hayashi, M., Fukazawa, M., Suzuki, I., and Nishimura, M. (2007). Cytosolic HSP90 regulates the heat shock response that is responsible for heat acclimation in Arabidopsis thaliana. J. Biol. Chem. 282, 37794-37804. doi: 10.1074/jbc.M707168200

Yamada, K., and Nishimura, M. (2008). Cytosolic heat shock protein 90 regulates heat shock transcription factor in Arabidopsis thaliana. Plant Signal. Behav. 3, 660-662. doi: 10.4161/psb.3.9.5775

Yamakawa, H., Katou, S., Seo, S., Mitsuhara, I., Kamada, H., and Ohashi, Y. (2004). Plant MAPK phosphatase interacts with calmodulins. J. Biol. Chem. 279, 928-936. doi: 10.1074/jbc.M310277200

Yan, H., Jia, H., Chen, X., Hao, L., An, H., and Guo, X. (2014). The cotton WRKY transcription factor GhWRKY17 functions in drought and salt stress in transgenic Nicotiana benthamiana through ABA signaling and the modulation of reactive oxygen species production. Plant Cell Physiol. 55, 2060-2076. doi: $10.1093 / \mathrm{pcp} / \mathrm{pcu} 133$

Yang, L., Ji, W., Zhu, Y., Gao, P., Li, Y., Cai, H., et al. (2010b). GsCBRLK, a calcium/calmodulin-binding receptor-like kinase, is a positive regulator of plant tolerance to salt and ABA stress. J. Exp. Bot. 61, 2519-2533. doi: $10.1093 /$ jxb/erq084
Yang, T., Chaudhuri, S., Yang, L., Chen, Y., and Poovaiah, B. W. (2004). Calcium/calmodulin up-regulates a cytoplasmic receptor-like kinase in plants. J. Biol. Chem. 279, 42552-42559. doi: 10.1074/jbc.M402830200

Yang, T., Chaudhuri, S., Yang, L., Du, L., and Poovaiah, B. W. (2010a). A calcium/calmodulin-regulated member of the receptor-like kinase family confers cold tolerance in plants. J. Biol. Chem. 285, 7119-7126. doi: 10.1074/jbc.M109.035659

Yang, T., and Poovaiah, B. W. (2002a). A calmodulin-binding/CGCG box DNAbinding protein family involved in multiple signaling pathways in plants. J. Biol. Chem. 277, 45049-45058. doi: 10.1074/jbc.M207941200

Yang, T., and Poovaiah, B. W. (2002b). Hydrogen peroxide homeostasis: activation of plant catalase by calcium/calmodulin. Proc. Natl. Acad. Sci. U.S.A. 99, 4097-4102. doi: 10.1073/pnas.052564899

Yang, T., Segal, G., Abbo, S., Feldman, M., and Fromm, H. (1996). Characterization of the calmodulin gene family in wheat: structure, chromosomal location, and evolutionary aspects. Mol. Gen. Genet. 252, 684-694. doi: 10.1007/BF021 73974

Yoo, C. Y., Pence, H. E., Jin, J. B., Miura, K., Gosney, M. J., Hasegawa, P. M., et al. (2010). The Arabidopsis GTL1 transcription factor regulates water use efficiency and drought tolerance by modulating stomatal density via transrepression of SDD1. Plant Cell, 22, 4128-4141. doi: 10.1105/tpc.110.078691

Yoo, J. H., Park, C. Y., Kim, J. C., Heo, W. D., Cheong, M. S., Park, H. C., et al. (2005). Direct interaction of a divergent CaM isoform and the transcription factor, MYB2, enhances salt tolerance in Arabidopsis. J. Biol. Chem. 280, 3697-3706. doi: 10.1074/jbc.M408237200

Yun, S. J., and Oh, S. H. (1998). Cloning and characterization of a tobacco cDNA encoding calcium/calmodulin-dependent glutamate decarboxylase. Mol. Cells $8,125-129$.

Zhang, L., Du, L., Shen, C., Yang, Y., and Poovaiah, B. W. (2014). Regulation of plant immunity through ubiquitin-mediated modulation of $\mathrm{Ca}^{2+}$ calmodulin-AtSR1/CAMTA3 signaling. Plant J. 78, 269-281. doi: 10.1111/tpj. 12473

Zhang, L., Liu, B. F., Liang, S., Jones, R. L., and Lu, Y. T. (2002). Molecular and biochemical characterization of a calcium/calmodulin-binding protein kinase from rice. Biochem. J. 368, 145-157. doi: 10.1042/bj20020780

Zhang, L., and Lu, Y. T. (2003). Calmodulin-binding protein kinases in plants. Trends Plant Sci. 8, 123-127. doi: 10.1016/S1360-1385(03)00013-X

Zhao, Y., Liu, W., Xu, Y. P., Cao, J. Y., Braam, J., and Cai, X. Z. (2013). Genomewide identification and functional analyses of calmodulin genes in Solanaceous species. BMC Plant Biol. 13:70. doi: 10.1186/1471-2229-13-70

Zhou, D. X. (1999). Regulatory mechanism of plant gene transcription by GTelements and GT-factors. Trends Plant Sci. 4, 210-214. doi: 10.1016/S13601385(99)01418-1

Zhu, X., Dunand, C., Snedden, W., and Galaud, J. P. (2015). CaM and CML emergence in the green lineage. Trends Plant Sci. 20, 483-489. doi: 10.1016/j.tplants.2015.05.010

Zik, M., Arazi, T., Snedden, W. A., and Fromm, H. (1998). Two isoforms of glutamate decarboxylase in Arabidopsis are regulated by calcium/calmodulin and differ in organ distribution. Plant Mol. Biol. 37, 967-975. doi: 10.1023/A:1006047623263

Zou, J., Guo, Y., Guettouche, T., Smith, D. F., and Voellmy, R. (1998). Repression of heat shock transcription factor HSF1 activation by HSP90 (HSP90 complex) that forms a stress-sensitive complex with HSF1. Cell 94, 471-480. doi: 10.1016/S0092-8674(00)81588-3

Conflict of Interest Statement: The authors declare that the research was conducted in the absence of any commercial or financial relationships that could be construed as a potential conflict of interest.

Copyright (c) 2015 Virdi, Singh and Singh. This is an open-access article distributed under the terms of the Creative Commons Attribution License (CC BY). The use, distribution or reproduction in other forums is permitted, provided the original author(s) or licensor are credited and that the original publication in this journal is cited, in accordance with accepted academic practice. No use, distribution or reproduction is permitted which does not comply with these terms. 